US Army Corps

of Engineers ${ }_{\circledast}$

Engineer Research and

Development Center

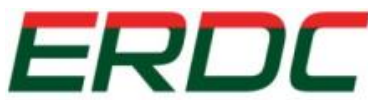

INNOVATIVE SOLUTIONS

for a safer, better world

Integrated Climate Assessment for Army Enterprise Planning

\title{
Development of a Predictive Corrosion Model Using Locality-Specific Corrosion Indices
}

Sean W. Morefield

September 2017
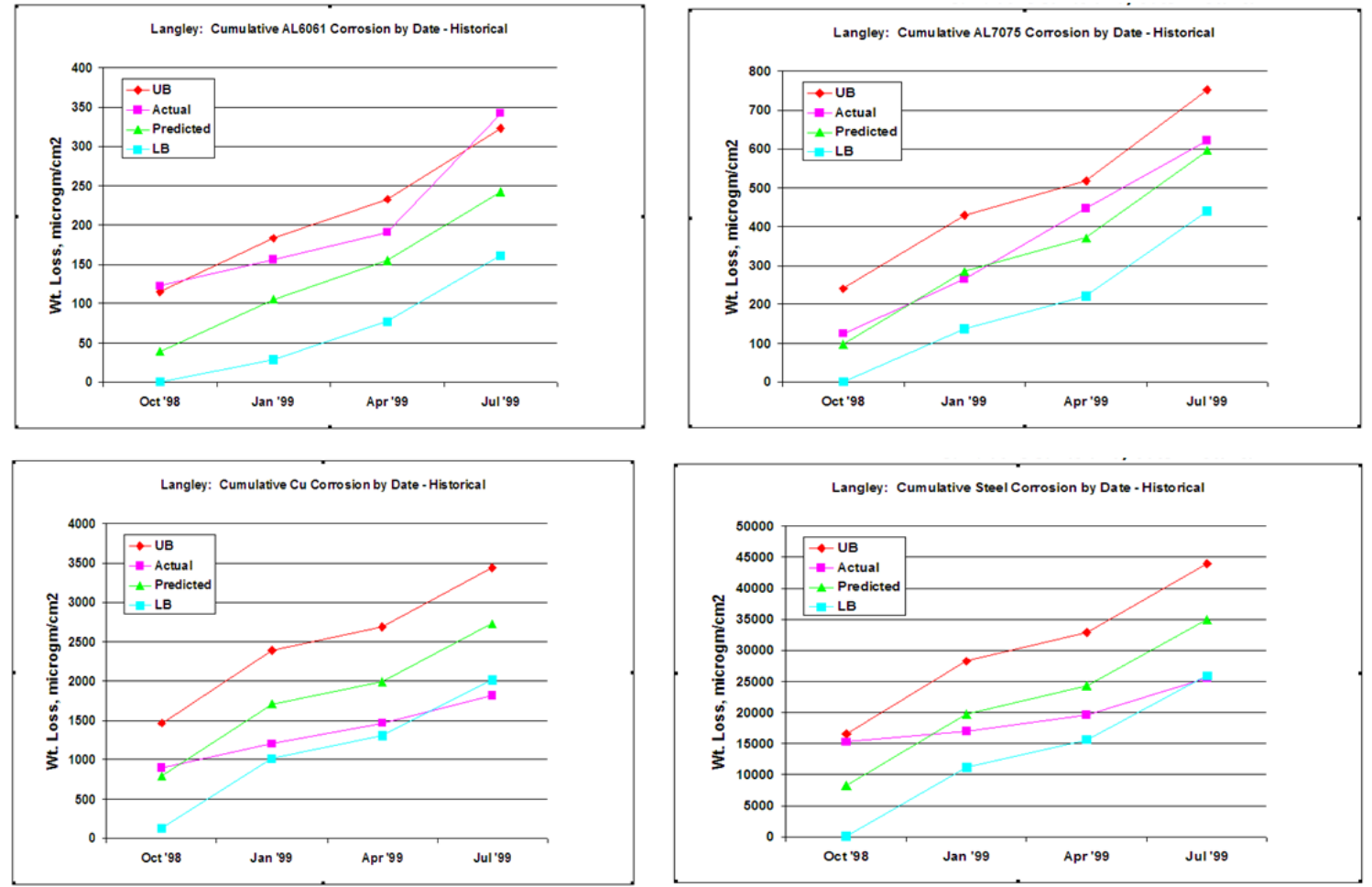

Approved for public release; distribution is unlimited. 
The U.S. Army Engineer Research and Development Center (ERDC) solves the nation's toughest engineering and environmental challenges. ERDC develops innovative solutions in civil and military engineering, geospatial sciences, water resources, and environmental sciences for the Army, the Department of Defense, civilian agencies, and our nation's public good. Find out more at www.erdc.usace.army.mil.

To search for other technical reports published by ERDC, visit the ERDC online library at http://acwc.sdp.sirsi.net/client/default. 


\section{Development of a Predictive Corrosion Model Using Locality-Specific Corrosion Indices}

Sean W. Morefield

U.S. Army Engineer Research and Development Center (ERDC)

Construction Engineering Research Laboratory (CERL)

2902 Newmark Dr.

Champaign, IL 61824

Final Report

Approved for public release; distribution is unlimited.

Prepared for Headquarters, U.S. Army Corps of Engineers

Washington, DC 20314-1000

Under Program 622720A896, "Environmental Quality Guidance," Work Package "Integrated Climate Assessment for Army Enterprise Planning," Work Unit L4F5G1, "Forecast Building Maintenance” 


\section{Abstract}

The U.S. Department of Defense has characterized the current approach to corrosion maintenance, which is based on simply finding and fixing damage before it becomes a concern, as inadequate to maintain missioncritical equipment and facilities to support stationing decisions. There is a need to go beyond corrosion prediction and management approaches to consider the impact of climate change on stationing decisions. To address this concern, there is a need to develop defensible, accurate approaches to project how certain installation metrics involving materials degradation are likely to change in the near future. The first step in creating a tool to meet this need is to determine how selected quantitative data, or chosen installation "metrics," will change over some specified period. This work developed and tested a corrosivity model capable of predicting corrosivity at specific sites.

DISCLAIMER: The contents of this report are not to be used for advertising, publication, or promotional purposes. Citation of trade names does not constitute an official endorsement or approval of the use of such commercial products. All product names and trademarks cited are the property of their respective owners. The findings of this report are not to be construed as an official Department of the Army position unless so designated by other authorized documents. 


\section{Contents}

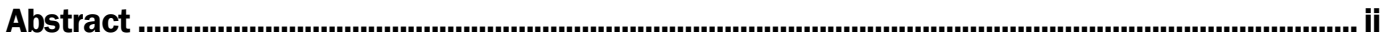

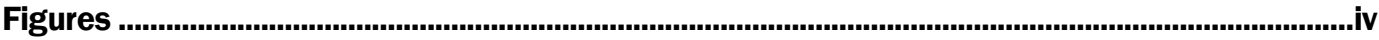

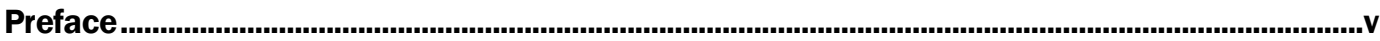

Unit Conversion Factors …......................................................................................................vi

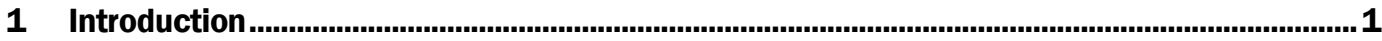

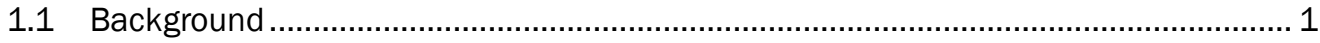

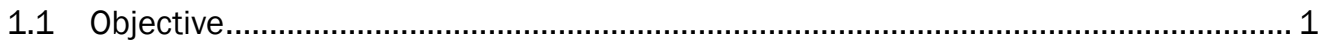

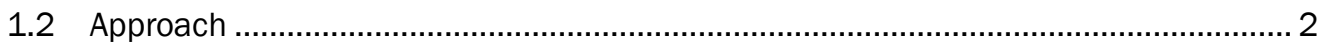

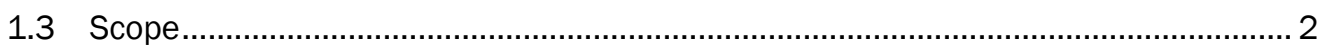

1.4 Mode of technology transfer .............................................................................. 3

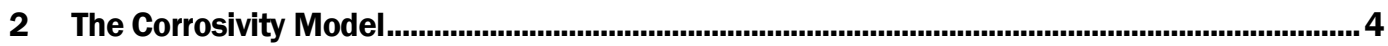

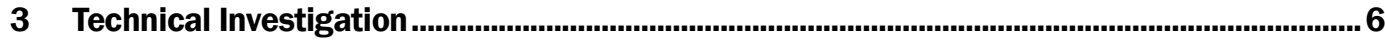

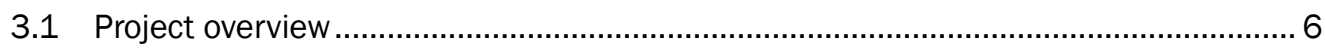

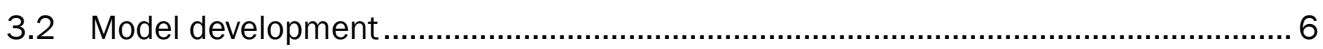

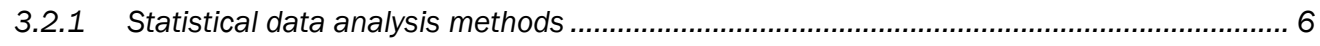

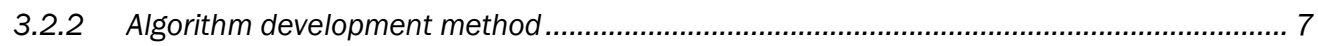

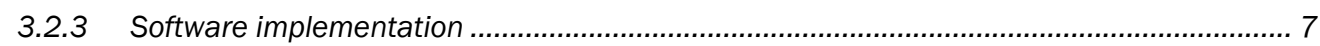

3.3 Model output examples .................................................................................. 8

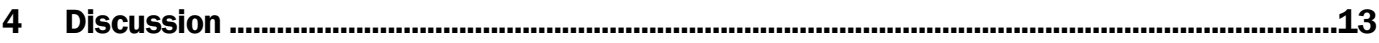

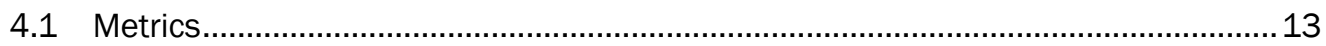

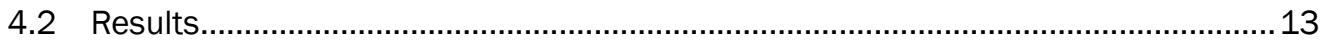

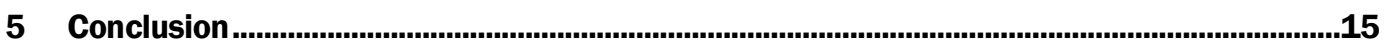

Appendix A: Detailed Model Development and Statistical Analysis ..............................................16

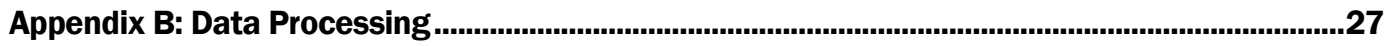

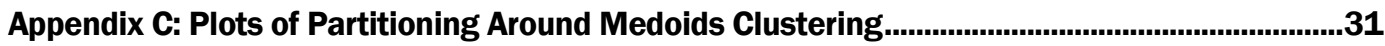

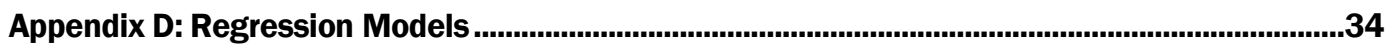

Appendix E: Plots of Regression Models for Selected Sites and Metals .......................................49

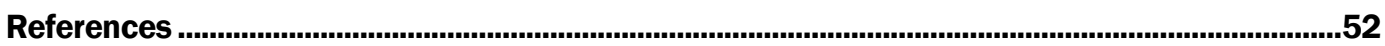

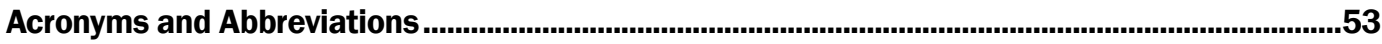

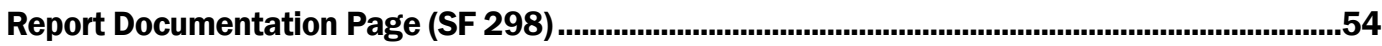




\section{Figures}

3-1 Screen output example for corrosion of $6061 \mathrm{Al}$ at Langley ..................................................

3-2 Screen output example for corrosion of $7075 \mathrm{Al}$ at Langley .................................................

3-3 Screen output example for corrosion of copper at Langley .................................................10

3-4 Screen output example for corrosion of steel at Langley.......................................................10

3-5 Predicted vs. actual graphing screen showing summary of current results for all

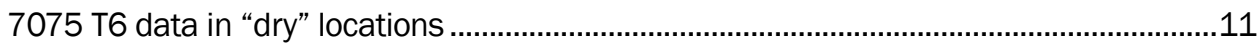

3-6 Predicted vs. actual graphing screen showing summary of current results for all 7075 T6 data in "wet" locations ....................................................................................11

3-7 Predicted vs. actual graphing screen showing summary of current results for all

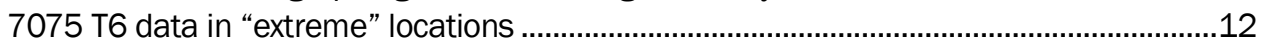

3-8 Plotting routine example for four Coast Guard stations and corrosion of 7075 T6 aluminum 


\section{Preface}

This study was conducted for Headquarters, U.S. Army Corps of Engineers (HQUSACE) under Program 622720A896, "Environmental Quality Guidance," Work Package "Integrated Climate Assessment for Army Enterprise Planning," Work Unit L4F5G1, "Forecast Building Maintenance.” The technical monitor was Sarah Harrop, Headquarters, Department of the Army (HQDA).

The work was performed by the Materials and Structures Branch (CEERDCFM), Facilities Division (CF), U. S. Army Engineer Research and Development Center - Construction Engineering Research Laboratory (ERDCCERL), Champaign, IL. At the time this report was prepared, the Chief of the ERDC-CERL Materials and Structures Branch was Vicki L. Van Blaricum (CEERD-CFM), the Chief of the Facilities Division was Donald K. Hicks, (CEERD-CF), and the Technical Director was Alan Anderson (CEERD-CZT). The Deputy Director of ERDC-CERL was Dr. Kirankumar Topudurti and the Director was Dr. Ilker Adiguzel.

COL Bryan S. Green was Commander of ERDC, and Dr. David W. Pittman was the Director. 


\section{Unit Conversion Factors}

\begin{tabular}{|l|c|l|}
\hline Multiply & By & To Obtain \\
\hline degrees Fahrenheit & $(\mathrm{F}-32) / 1.8$ & degrees Celsius \\
\hline feet & 0.3048 & meters \\
\hline gallons (U.S. liquid) & $3.785412 \mathrm{E}-03$ & cubic meters \\
\hline inches & 0.0254 & meters \\
\hline mils & 0.0254 & millimeters \\
\hline square feet & 0.09290304 & square meters \\
\hline
\end{tabular}




\section{Introduction}

\subsection{Background}

Historically, the Department of Defense (DoD) has not made long-term planning and stationing decisions based on climate change. However, the Center for Army Analysis (CAA) has recently expressed its concern regarding how climate change may impact facility operations and maintenance (O\&M), and how the military can make smarter stationing decisions that allay those impacts. One important part of facility O\&M is the prevention and treatment of corrosion.

In the past, corrosion maintenance has commonly been based on simply finding and fixing damage before it becomes a structural or safety concern. DoD has identified this approach as inadequate to maintain missioncritical equipment and facilities to support stationing decisions involving deployment, training, and readiness. In other words, concerns for corrosion, which have previously focused primarily on maintenance costs, have shifted to include structural integrity and safety. This shift has dictated a change to prediction and management approaches that go beyond finding and fixing corrosion faults, and minimizing the associated costs. More specifically, there is now both an interest and directives to consider the impact of climate change on stationing decisions.

To address this concern, there is a need to develop defensible, accurate approaches to project how certain installation metrics involving materials degradation are likely to change in the near future (i.e., over the next 4 decades). To date, there has been little emphasis on developing the engineering tools needed to manage corrosion and its associated maintenance and repair actions. The tools that are available do not consider how climate change may impact facility maintenance and operations. The first step in creating such a tool is to determine how selected quantitative data, or chosen installation "metrics," will change over some specified period.

\subsection{Objective}

The objective of this work was to develop defensible, accurate approaches to project how the chosen installation metrics are likely to change over the next 4 decades. 


\subsection{Approach}

1. ERDC-CERL developed the corrosivity model used in this project jointly with the Office of the Secretary of Defense (OSD), Installation Management Agency (IMA), and Air Force Office of Aging Aircraft and Battelle (Chapter 2).

2. Datasets were identified and obtained to make an atmospheric corrosivity model that was capable of predicting the corrosivity of the sites not included in the exposure data project (Chapter 3).

3. Software implementation environments (coding language, application components, and method) were compiled into an executable program that uses mathematical models of materials degradation, and statistical calculations that rely on the identification of results of Army selected global circulation model (GCM) results after running Army selected greenhouse gas emission scenarios. These changes are expressed in terms of percent increases or decreases in the value of currently accepted cost metrics.

4. Model output was generated, analyzed, and compared with previous atmospheric models (Chapters 3 and 4).

5. Supplementary information includes:

a. Appendix A, which describes the general framework and a more detailed model development, as well as a statistical analysis (Chapter 2)

b. Appendix B, which details how the atmospheric and weather data were clustered and processed

c. Appendix C, which gives a graphical representation of how the weather data were partitioned around medoids

d. Appendix D, which details the specific code used to create the model

e. Appendix E, which presents select outputs of the model, may be used to compare the predicted corrosion loss with the observed corrosion data for selected sites and metals with regression plot.

\subsection{Scope}

Although the primary purpose of this work is to support CAA stationing questions, other Army professional groups may benefit from this work, e.g., Facility Engineers benefit from having good information in making appropriate material selection choices and Facility Planners benefit from accurate severity factors to make economic decisions for maintenance. 


\subsection{Mode of technology transfer}

It is anticipated that the results of this work will provide a foundation for follow-on research in support of CAA Army stationing analyses (restructuring and realignment analysis). It is anticipated that the results of this work, when combined with CAA feedback, will support CAA subject matter experts in Comprehensive Omnibus Budget Reconciliation Act (COBRA) and Optimal Stationing of Army Forces (OSAF) models. Further Collaboration with the U.S. Army Materiel Systems Analysis Activity (AMSAA) will continue to share model improvements and datasets. 


\section{The Corrosivity Model}

ERDC-CERL developed the corrosivity model used in this project jointly with OSD, IMA, and the Air Force Office of Aging Aircraft and Battelle. The corrosivity model consists of a series of data partitions and regressions built on empirical measurements taken from over 2 decades of coupon rack placement, at weapons platforms and facilities, using sheltered and unsheltered racks. Weather data were incorporated from Air Force Combat Climatology Center (AFCCC) and state sources. This research uses climate models of record provided by researchers at the Engineer Research and Development Center, Cold Regions Research and Engineering Laboratory (ERDCCRREL). Estimated climate variables from those models will serve as inputs into the corrosivity model to estimate future corrosivity at a given location.

AMSAA recently worked with the corrosivity model and made several improvements to it. They updated the model with several new corrosivity factors including airborne particulate, sulfides, and nitrate compounds. They also integrated the improved model into a Geographic Information System (GIS) framework and developed an algorithm to interpolate corrosivity for regions in between coupon sampling locations. AMSAA partnered with ERDC-CERL and has expressed its willingness to share its updated data framework, which this project will use as the basis for the corrosivity projection model.

However, the baseline and projected corrosivity calculations still need to be translated into a cost impact factor. To meet this need, the Army Integrated Facilities System (IFS) database will provide information on facility type, area, cost, and (where available) baseline condition for each installation under study. Current maintenance costs will be mapped to the present corrosivity calculation. Future maintenance costs are estimated to scale with the projected corrosivity values. The ratio of current cost factors and current corrosivity rates are treated as linearly proportional to future corrosivity rates and cost factors.

The corrosivity model quantifies the severity of atmospheric corrosion that takes into account different geographic locations, local weather conditions, and distance from a sea coast. The model allows the corrosion index to be queried for a particular location included in the survey. The model can also predict the corrosivity of other new locations not included in the surveyed locations. 
The model was created from several different data sources. The raw atmospheric corrosion data came from a previously funded project AR-F-311 "Measuring the Rates and Impact of Corrosion on DoD on Equipment and Installations" (Drozdz, Abbot, and J ackson 2007). Additional atmospheric corrosion data came from other DoD projects that used the same sample form factor that made the data integration transparent. Local weather data were incorporated from open sources such as the AFCCC and from reliable state and private sources.

Statistical data analysis methods, expressed in concise and plain language, were used to examine worldwide coupon data. The same statistical analysis methods were used to examine weather and location data and the raw data collected from the earlier project. The atmospheric corrosion data collected from analyzed samples were empirically correlated against the weather severity aggregated data collected from the site.

A complete set of 12-month cumulative weather data for the 160 sites were subjected to a classification algorithm known as Partitioning Around Medoids (PAM). This methodology selects a number of desired data subgroups and calculates the routine that evaluates the quality of that choice for a specific number of partitions. The weather data parameters examined included relative humidity, precipitation, and atmospheric deposition of chlorides. The analysis conducted on the available weather data examined the consequences of choosing two, three, and four groupings. It was found that the 12-month weather data were optimally clustered into three distinct groupings: dry, wet, and severe.

An algorithm development method for the atmospheric corrosion model was developed using empirical regression. The measured corrosion rate for each metal type was correlated to the weather data from its location. The resulting empirical fit parameters constitute the model. The corrosivity model was developed using commonly accessible software implementation environments, coding language, application components, and methods and/ or tools to compile the components into an executable program. The clustered weather data and atmospheric corrosion data are stored in an Excel spreadsheet. The software interface is built around an MS Access ${ }^{\circledR}$ database, which has been tested under a number of versions of Windows. 


\section{Technical Investigation}

\subsection{Project overview}

Datasets from several other variables were needed to make an atmospheric corrosivity model that was capable of predicting the corrosivity of the sites not included in the exposure data project. Specifically, historic data from weather stations were collected from the weather agency closest to the sample exposure rack was collected. The distance from the weather station to the exposure rack was also noted. Variables including humidity, precipitation, temperature, and humidity were all acquired for the period of rack exposure. Weather data were obtained from open sources such as the AFCCC and from state, local, and private sources.

The atmospheric corrosion rate database was assembled to begin the statisti$\mathrm{cal}$ analysis. The model and database are constructed to allow new data to be added as they become available. However, given the magnitude of data already incorporated, additional data should have little impact on the model.

The statistical analyses of the weather data consisted of partitioning along medoids. This analysis aggregates the weather into groups that display coherency. Appendix E includes additional detail. The models were developed and implemented as a computer application.

\subsection{Model development}

The corrosion indices and predictive algorithms were developed for application to metals exposed to the open atmosphere, unsheltered.

\subsubsection{Statistical data analysis methods}

Statistical data analysis methods were used to correlate weather and location data with worldwide coupon data. The atmospheric corrosion data collected from analyzed samples were empirically correlated against the weather severity aggregated data collected from the site.

A complete set of 12-month cumulative weather data for the 160 sites was subjected to the classification algorithm known as PAM. In this methodology, a number of desired data subgroups are selected; the routine calculates how good a choice that number of partitions is. The weather data pa- 
rameters examined included relative humidity, precipitation, and atmospheric deposition of chlorides. The analysis conducted on the available weather data examined the consequences of choosing two, three, and four groupings. It was found that the 12-month weather data were optimally clustered into three distinct groupings: dry, wet, and severe.

\subsubsection{Algorithm development method}

The algorithm development method was designed for simplicity, i.e., to be concise and plain enough for an experienced Excel user to understand. The atmospheric corrosion model was developed by means of empirical regression. The measured corrosion rate for each metal type was correlated to the weather data from its location. The resulting empirical fit parameters constitute the model.

\subsubsection{Software implementation}

The software implementation environments, coding language, application components (files and databases), and method and/ or tool were compiled into an executable program. The clustered weather data and atmospheric corrosion data are stored in an Excel spreadsheet. The software interface is based on an MS Access ${ }^{\circledR}$ database, which was tested under several versions of Windows.

Data analyses have shown that the environments worldwide can be partitioned into three broad categories depending on the combinations of humidity and atmospheric chlorides. For descriptive purposes, these will be termed "Extreme," "Wet," and "Dry." The categories are derived from a weighted average of humidity, rainfall, and chlorides for a location. Appendix B expands on the quantitative definitions of these categories.

Algorithms were developed for each of these categories to give more precise predictions. Although the algorithms are described explicitly in this report, the processes in the executable program will be transparent to the end user. Correlation coefficients have been calculated for each metal and weather grouping; these appear to be in the range of 0.75 . This is considered quite good for work of this type and represents a significant advance over prior published work such as the PACER LIME model (Summitt and Fink 1980) and others, which have achieved coefficients no better than 0.5 . 


\subsection{Model output examples}

Figures 3-1 to 3-4 show examples of graphical output for each of four metals at a single site. The model had to be run separately for each of the metals. In these cases the agreements between actual and predicted corrosion is relatively good. Generally, most data fall within the $95 \%$ confidence intervals.

Note that cases will be found in which the agreement is not as good and where actual values lie above the upper limits. The reasons for this have often been resolved; in the most general case, the discrepancy may be attributed to the (external) source of the available weather data, i.e., they were recorded by other parties. There is a fundamental assumption/ requirement in any work of this type in which the weather and corrosion data are coincident in time (usually not a problem) and location. In the event that the locations are not identical/very close, it would be a judgment call whether the weather data should be applicable to the monitored location. This problem is most likely to occur in coastal regions where monitoring is occurring within the first $1 / 2$ mile or so of the coast. Often, the weather station will be somewhat further inland and not near the corrosion samples. In these cases, the measured corrosion rates are likely to be much higher than predicted values, since it has been shown that corrosion rates may vary almost exponentially with distance from ocean within at least the first half-mile.

Figures 3-5 to 3-7 show the results of such plots for $7075 \mathrm{~T} 6$ aluminum according to the site data currently in the embedded MS Access ${ }^{\circledR}$ database. A "perfect" correlation would be for all data to cluster around a 45 degree line for each condition. In reality the results are quite good, particularly in consideration of the fact that these are real field data. A few outliers are shown for each case. The reasons for most of these outliers are generally known. However, for information purposes, this investigation examined whether there is a simple way for the user to identify these sites by simply indicating a specific plotted point, as one might do in an Excel plot.

Figure 3-8 shows output of corrosion kinetics for four Coast Guard stations. Predicted cumulative corrosion is plotted at 3-month intervals. (One 3-month interval equals one sequence for this plot.) The slope of the line indicates the corrosion rate for that material and location. Higher slopes indicate a greater corrosivity. 
Figure 3-1. Screen output example for corrosion of $6061 \mathrm{Al}$ at Langley.

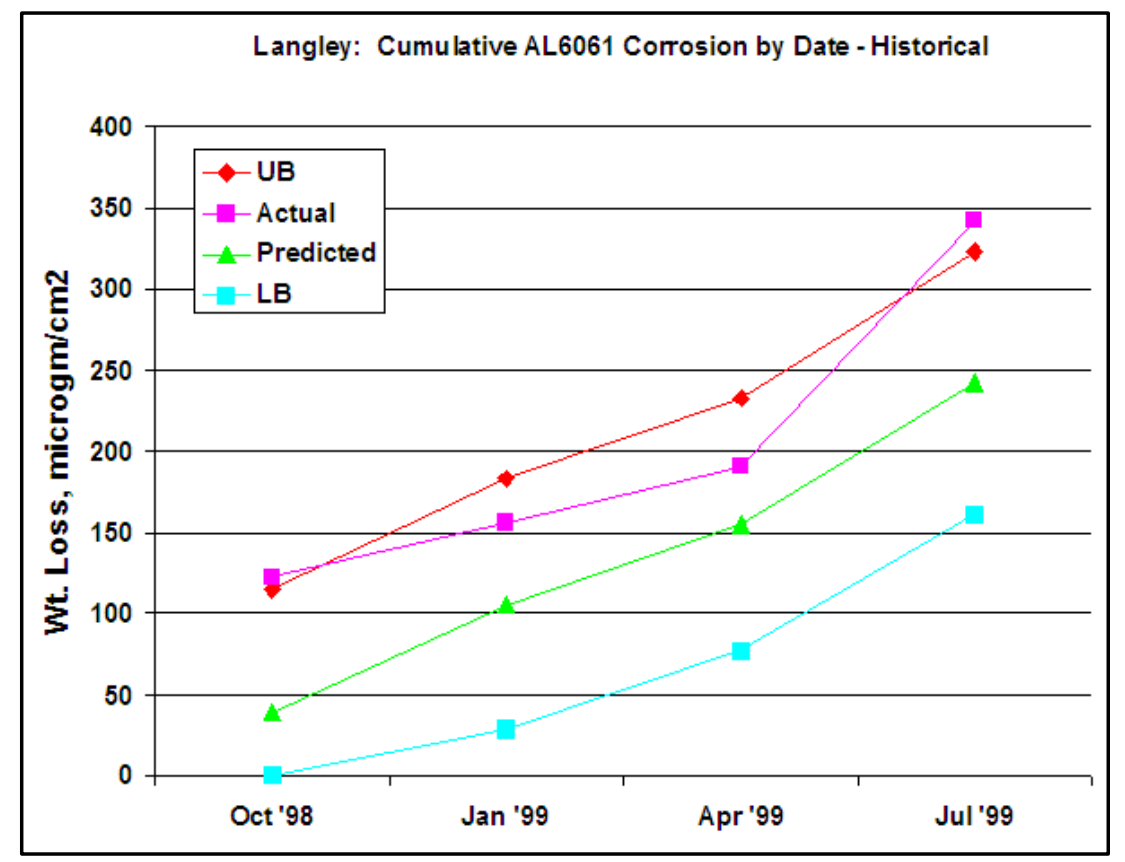

Figure 3-2. Screen output example for corrosion of 7075 Al at Langley.

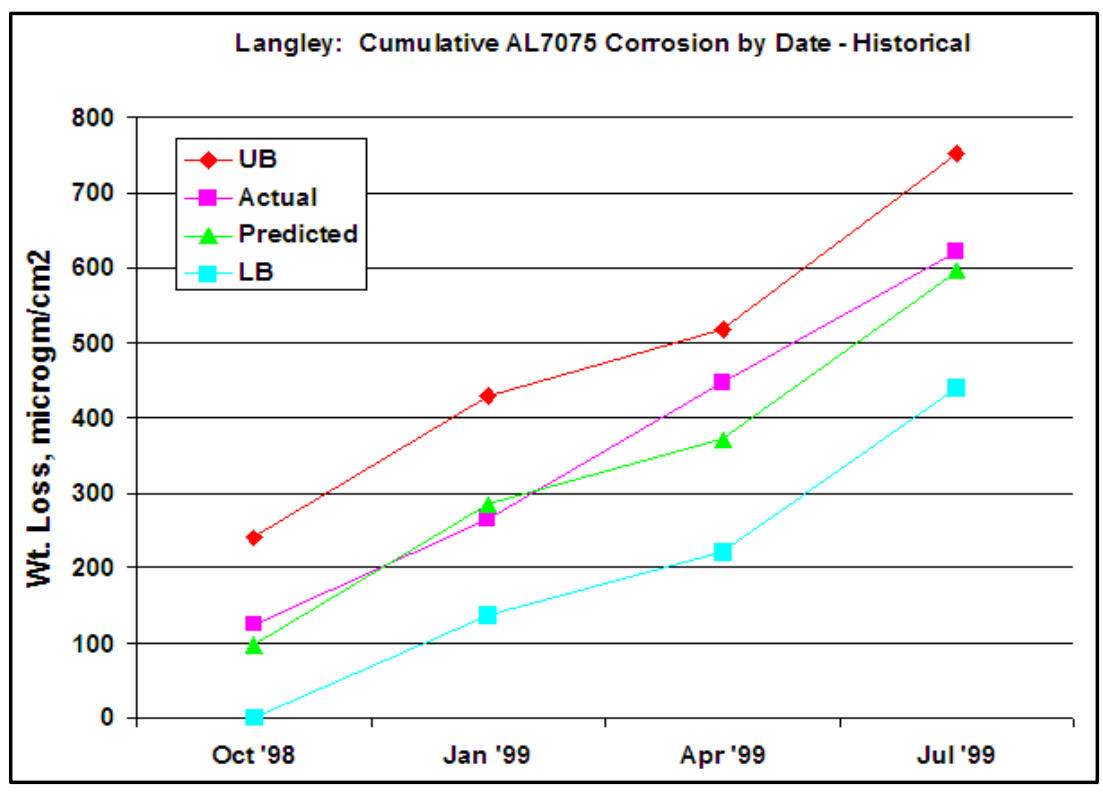


Figure 3-3. Screen output example for corrosion of copper at Langley.

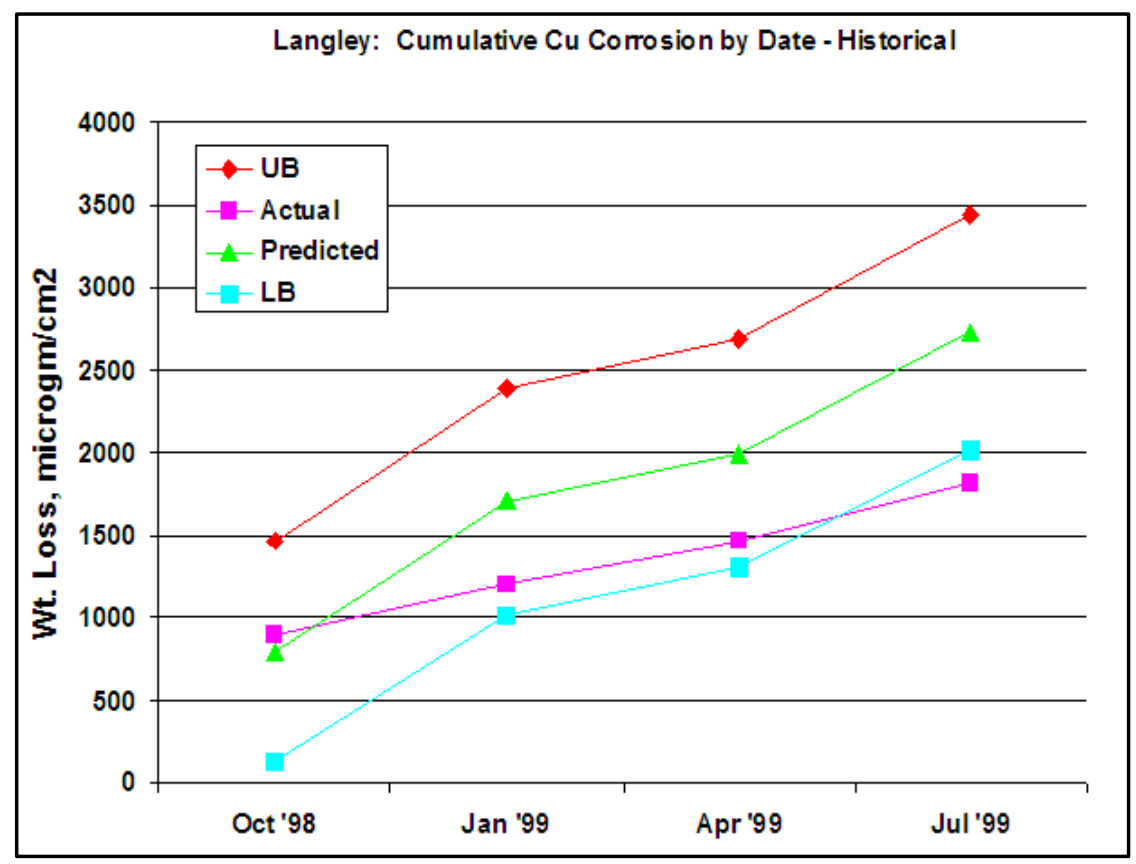

Figure 3-4. Screen output example for corrosion of steel at Langley.

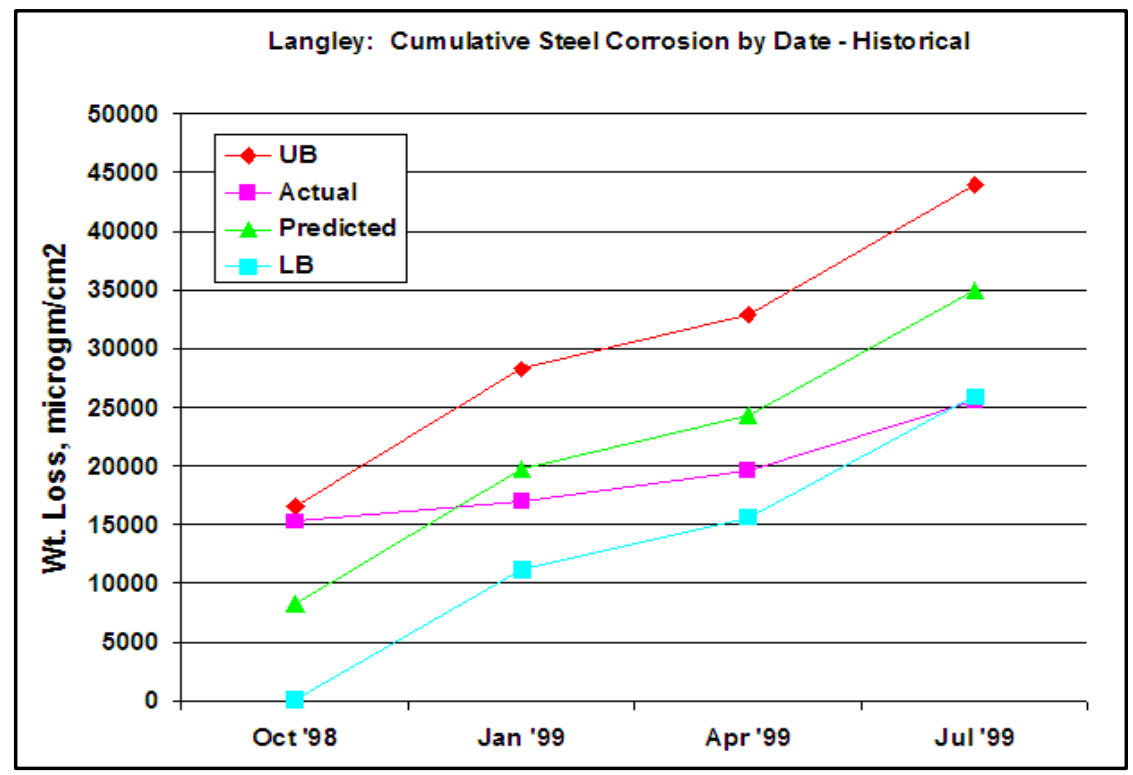


Figure 3-5. Predicted vs. actual graphing screen showing summary of current results for all 7075 T6 data in "dry" locations.

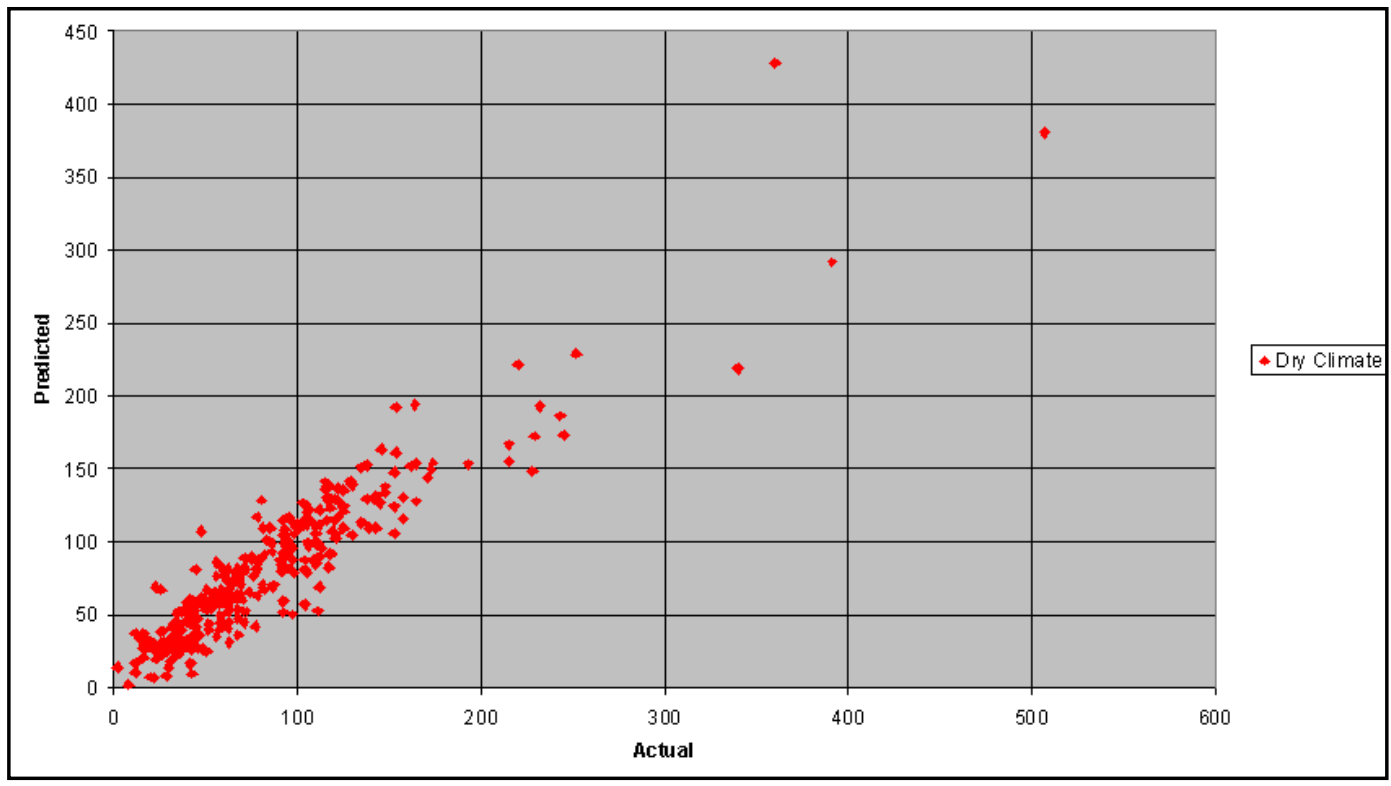

Figure 3-6. Predicted vs. actual graphing screen showing summary of current results for all 7075 T6 data in "wet" locations.

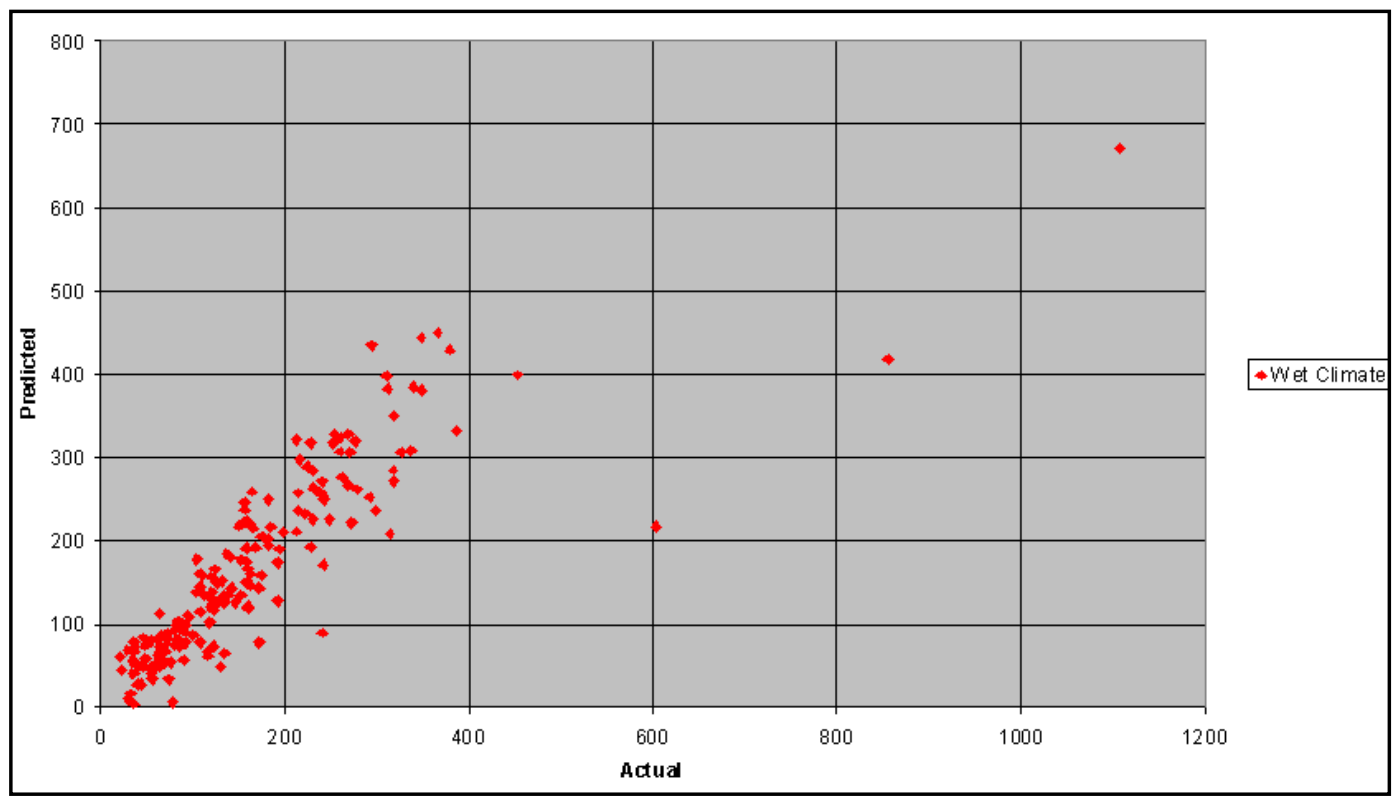


Figure 3-7. Predicted vs. actual graphing screen showing summary of current results for all 7075 T6 data in "extreme" locations.

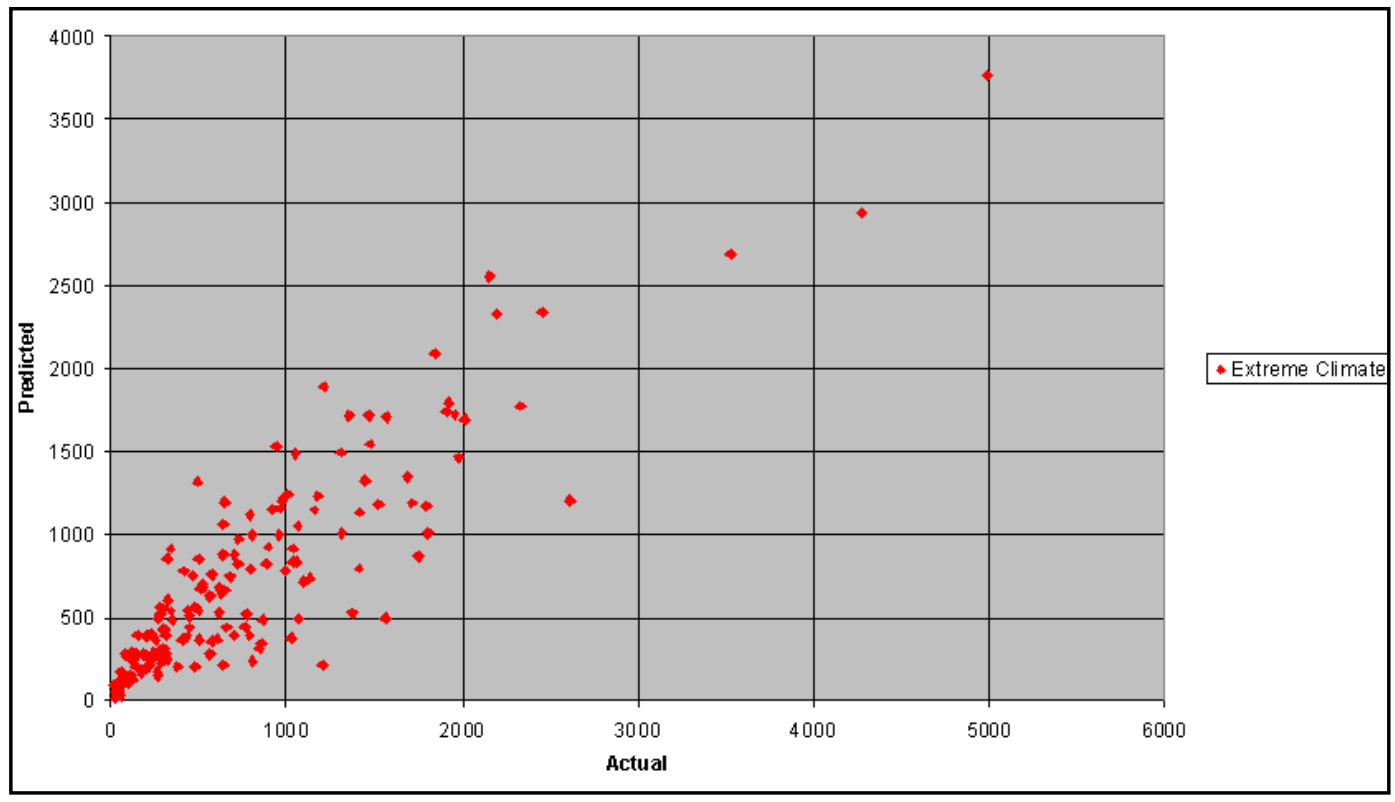

Figure 3-8. Plotting routine example for four Coast Guard stations and corrosion of 7075 T6 aluminum.

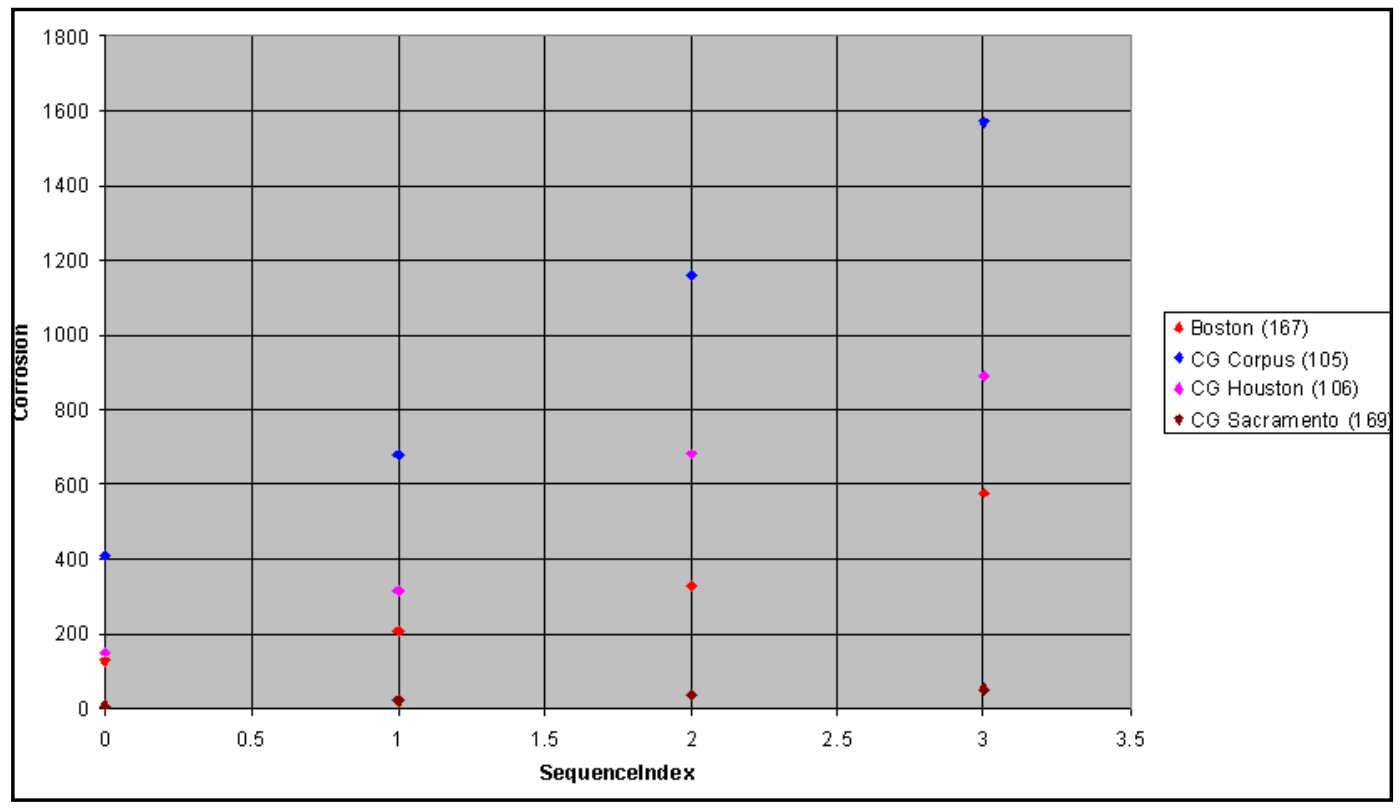




\section{Discussion}

\subsection{Metrics}

The corrosion severity model is based on quantitative data on environmental corrosivity collected through atmospheric exposure of standardized metallic corrosion specimen sets and statistically correlated with their corresponding climate and geospatial data. The reference metrics employed in this work were:

- The corrosion test racks provided a consistent atmospheric test methodology to gather the data used in the model. The specific panel methodology is also described in Drozdz, Abbott, and J ackson (2007).

- Alloy composition standards for the sample metals are as published by American Society for Testing and Materials (ASTM) International ASTM B308/ B308M-02 (2010), ASTM A108 (2013a), and ASTM B152 (2013b) for Aluminum, Steel, and Copper samples respectively. The specific alloys used were copper, $6061 \mathrm{~T} 6$ aluminum, $7075 \mathrm{~T} 6$ aluminum, and a low carbon (1010) steel.

- Weather data compiled from the AFCCC, and state weather organizations.

The primary metric used to validate the model was statistical analysis of its application to specific geospatial locations, comparing the severity index with the observed data. A comparison of the actual cumulative corrosion levels to the $95 \%$ prediction intervals associated with the models demonstrates that the actual cumulative corrosion levels are contained within them $83.7 \%$ of the time. Overall, this agreement indicates that this model surpasses previous atmospheric models such as the PACER LIME in that it is more accurate, and more comprehensive in scope. Appendix E details this "internal challenge" method more fully.

\subsection{Results}

The change in corrosion for a given metal at a given site from the end of the preceding observation period to the end of the current observation period was regressed on the concomitant variables given in Table A-9 for each metal and weather group. This yielded a total of 15 regression models (described in Appendix E). Appendix E includes the regression coefficients, ttests, adjusted R2, and other model details. The data in Table A-10 describe 
the properties of these models, and indicate that 11 of the 15 models have excellent adjusted R2 values (greater than $72.3 \%$ in all cases). The predominance of the good explanatory power of the variables listed in Table A-9 suggests that the variable selection method worked (see Section A.3.2.2). 


\section{Conclusion}

This work has produced an operational corrosion rate predictive model based on indices developed through statistical analysis of a large database of empirical corrosion and weather records. Software implementations of the model are available for the metals included on the Battelle corrosion measurement specimens described in Chapter 1, specifically, copper, 6061 T6 aluminum, $7075 \mathrm{~T} 6$ aluminum, and a low carbon (1010) steel. The large databases compiled for this project are available to researchers and other parties interested in developing refinements or further applications based on the corrosion indices and predictive model.

The corrosion indices and predictive models may be used to estimate corrosion rates for the subject metals at field sites worldwide. This has proved to be important for new bases where there has been no prior history of operations or corrosion monitoring. All that is normally required is a minimal amount of weather data, which is almost always available wherever there are maneuver training and flight operations. 


\section{Appendix A: Detailed Model Development and Statistical Analysis}

\section{A.1 Introduction}

Bare metal coupons -Aluminum 2024, Aluminum 6061, Aluminum 7075, Steel, and Copper - have been placed in widely varied locations around the globe. At regular intervals the cumulative corrosion in these metals has been measured, along with time of measurement. In addition, data have been obtained from public sources for other concomitant variables. These include percent time that relative humidity exceeded $70 \%, 80 \%$, and $90 \%$ between the end of the previous time interval and the end of the current time interval; and cumulative precipitation through the end of current time interval. A measure of cumulative atmospheric chloride exposure through the end of the current time interval was also obtained from exposure of silver sensors. These data have been stored in a previously developed MS Access ${ }^{\circledR}$ database application and are available for querying.

The goal of this study is to develop a regression analysis of the corrosion levels of the various metals as a function of the critical environmental variables as defined in earlier analyses. As a first step, natural clusterings of overall weather type will be determined so that the regression models for corrosion change can be optimized to take fundamental weather "types" into account. A linear discriminant analysis will be used to build classification rules for these weather types so that, as new locations are added to the database, they may be appropriately classified according to the weather that predominates at those locations. The latter will be predominantly military bases worldwide.

The regression strategy is to build a model for the change in corrosion, of a given metal at a site having a known weather type, from the end of one time interval to the end of the subsequent time interval. The form of this model is linear and its structure is motivated by previous work conducted in 2003. This metal- and weather-specific model may then be used to iteratively compute predictions for the cumulative corrosion in the given metal, over time, for a given site and specific concomitant variable values. The associated prediction intervals may also be built. It is desirable to obtain a tractable set of regression models, ideally having the same structure. 


\section{A.2 Data handling}

\section{A.2.1 Data transfer}

Data were extracted by employees of Battelle Memorial Institute, from a MS Access ${ }^{\circledR}$ database application via table queries. The data were transferred via unsecured email by Bill Abbott (abbott@battelle.org) to David Paul, Ph.D. (david alan paul@yahoo.com) in the files listed in Table A-1.

Table A-1. Data files and brief descriptions.

\begin{tabular}{|l|l|}
\hline File Name & Description \\
\hline All_AL2024_Data_1207.xls & AL2024 corrosion data only \\
\hline qry_BaseResponsealldata_rev307.xls & Contains corrosion data, except for AL2024 \\
\hline gry_BaseExplanatory_alldata.xls & Concomitant variables \\
\hline
\end{tabular}

\section{A.2.2 Data processing and variable definitions}

All data processing and statistical analyses were performed on a computer running WinXP Professional, SP2. The data were converted to commadelimited format (*.txt) and imported into an electronic database suitable for manipulation and statistical analysis. A substantial amount of data processing was required to build a database suitable for the statistical analysis. The details of these efforts are included in Appendix C. Table A-2 lists the variables included in the final database that are vital to the statistical analysis described in the next section,

Table A-2. Description of key variables.

\begin{tabular}{|l|l|}
\hline Variable Name & Definition \\
\hline AFBASE & Name of geographic location/military base. \\
\hline ID & $\begin{array}{l}\text { The ID (identification) value of the Air Force base. Valid values } \\
\text { are from 1 to 243 by the software at time of data import. }\end{array}$ \\
\hline METAL & $\begin{array}{l}\text { The type of metal being considered - AL2024, AL6061, } \\
\text { AL7075, Steel, and Cu are the valid values for this variable. }\end{array}$ \\
\hline TIMECHG & $\begin{array}{l}\text { Denotes the length of time, in months, between the end of the } \\
\text { preceding observation period and the end of the current } \\
\text { observation period. TIMECHG is typically 3.0 months. }\end{array}$ \\
\hline TIME & $\begin{array}{l}\text { The cumulative elapsed time, in months, between TIME }=0 \\
\text { and the end of the current observation period. }\end{array}$ \\
\hline RH70CHG / & $\begin{array}{l}\text { RHxCHG is defined to be the percentage of time the relative } \\
\text { humidity exceeded } \mathrm{x} \% \text { from the end of the preceding } \\
\text { observation period to the end of the current observation } \\
\text { period. }\end{array}$ \\
\hline RH70CHG / RH80 / RH90 & $\begin{array}{l}\text { RHx is the percentage of time the relative humidity exceeded } \\
\mathrm{x} \% \text { from TIME }=0 \text { to the end of the current observation period. }\end{array}$ \\
\hline
\end{tabular}




\begin{tabular}{|l|l|}
\hline Variable Name & Definition \\
\hline PRECIPCHG & $\begin{array}{l}\text { The precipitation, in inches, from the end of the preceding } \\
\text { observation period to the end of the current observation } \\
\text { period. }\end{array}$ \\
\hline PRECIP & $\begin{array}{l}\text { The cumulative precipitation, in inches, from TIME }=0 \text { to the } \\
\text { end of the current observation period. }\end{array}$ \\
\hline CHLORIDECHG & $\begin{array}{l}\text { The atmospheric chloride exposure, measured in Å of silver } \\
\text { chloride accumulated on silver sensors, from the end of the } \\
\text { preceding observation period to the end of the current } \\
\text { observation period. }\end{array}$ \\
\hline CHLORIDE & $\begin{array}{l}\text { The cumulative chloride exposure, measured in A of silver } \\
\text { chloride accumulated on silver sensors, from TIME = 0 to the } \\
\text { end of the current observation period. }\end{array}$ \\
\hline CORROSION_LAG & $\begin{array}{l}\text { The cumulative corrosion for a given metal at a given site from } \\
\text { TIME }=0 \text { to the end of the preceding observation period. }\end{array}$ \\
\hline CORROSION & $\begin{array}{l}\text { The cumulative corrosion for a given metal at a given site from } \\
\text { TIME }=0 \text { to the end of the current observation period. }\end{array}$ \\
\hline CORRCHG & $\begin{array}{l}\text { The change in corrosion for a given metal at a given site from } \\
\text { the end of the preceding observation period to the end of the } \\
\text { current observation period. }\end{array}$ \\
\hline DATTYPE1 & $\begin{array}{l}\text { Indicates if the data came from the older method of } \\
\text { observation (prior to 2004) or the newer method. }{ }^{\dagger}\end{array}$ \\
\hline $\begin{array}{l}\text { t Older method refers to practice of starting exposures of four sample sets at the same time in a test rack with planned } \\
\text { removals at 3-month intervals over a 1-year period. Newer method refers to practice of exposing only one sample set } \\
\text { at a time and exchanging every } 3 \text { months. These procedures may result in subtle differences in corrosion rates. } \\
\text { Sample sets with ID<150 represent the older method. }\end{array}$ \\
\hline
\end{tabular}

\section{A.3 Statistical analysis}

\section{A.3.1 Weather clusters and linear discriminant analysis}

The humidity, precipitation, and chloride exposure at a particular location may be summarized using the 12-month cumulative humidity, precipitation, and chloride exposure at the site. This eliminates seasonal effects in the weather data.

Of the 177 total locations in the database, 12-month cumulative weather data are available in some form for 160 of these sites. This implies that 17 sites will remain unclassified according to weather type, and will not contribute to the subsequent regression modeling. Of the 160 sites having $12-$ month weather data (Table A-3), AL6061 records are predominant (not all metals were observed at equal time intervals). 
Table A-3. Amount of 12-month weather data available, by metal.

\begin{tabular}{|l|c|}
\hline Metal & $\begin{array}{c}\text { Proportion of Sites Having 12-Month } \\
\text { Cumulative Weather Data }\end{array}$ \\
\hline AL2024 & $62 / 160$ \\
\hline AL6061 & $156 / 160$ \\
\hline AL7075 & $137 / 160$ \\
\hline Steel & $139 / 160$ \\
\hline Cu & $99 / 160$ \\
\hline
\end{tabular}

The four sites not represented by AL6061 12-month cumulative weather measurements were "New Orleans 03 (208)," "Amberley02 (103)," "Stirling 02 (130)," and "Williamtown02 (132)." Table A-4 lists the metals for which weather data are available for these sites.

Table A-4. Metal-records providing 12-month cumulative weather data for those sites not represented by AL6061.

\begin{tabular}{|l|c|}
\hline Site Name & $\begin{array}{c}\text { Metals for Which 12-month Cumulative } \\
\text { Weather Data are Available }\end{array}$ \\
\hline New Orleans 03 (208) & AL2024 \\
\hline Amberley02 (103) & AL7075, Steel \\
\hline Stirling 02 (130) & AL7075, Steel \\
\hline Williamtown02 (132) & AL7075, Steel \\
\hline
\end{tabular}

Therefore, 12-month cumulative weather data from AL6061 records were augmented with records from AL2024 and AL7075 to form a complete set of available 12-month cumulative weather data for the 160 sites actually contributing such data. These data were subjected to the classification algorithm known as PAM. In this methodology, the user specifies the number of desired groupings, and the method then derives the optimal allocation of these groupings to the various Air Force bases. The analysis conducted on the available weather data examined the consequences of choosing two, three, and four groupings. Table A- 5 lists the variables used in this classification analysis.

It was found that the 12-month weather data were optimally clustered into three distinct groupings. Graphical analyses and text supporting this claim may be found in Appendix D. Table A-6 lists the distributions of key variables within these three groupings. Weather Group 1 may be considered "extreme" with respect to chloride exposure; Weather Group 2 may be 
considered "wet" because it exhibits the highest RH70 and PRECIP median values; and Weather Group 3 may be considered "dry" since it has the lowest RH70 and second lowest PRECIP median values.

It is of interest to note that the distribution of the DATTYPE1 variable is not uniform across the three groupings of weather data. A DATTYPE1 value of one (1) indicates that the data were collected using the newer method of sampling, while a value of zero (0) indicates that the data were collected using an older method. This detail is presented for information purposes, but in the final software available to users this distinction will be transparent.

Table A-5. Variables used to classify sites according to 12-month weather data

\begin{tabular}{|l|l|}
\hline Variable Name & Definition \\
\hline ID & The ID value of the location. \\
\hline METAL & Data restricted to AL6061, AL2024, and AL7075 records. \\
\hline TIME & Data restricted to TIME = 12 records. \\
\hline RH70 & $\begin{array}{l}\text { RH70 is the percentage of time the relative humidity } \\
\text { exceeded 70\% from TIME = 0 to TIME }=12 .\end{array}$ \\
\hline PRECIP & $\begin{array}{l}\text { The cumulative precipitation, in inches, from TIME = 0 to } \\
\text { TIME }=12 .\end{array}$ \\
\hline CHLORIDE & $\begin{array}{l}\text { The cumulative chloride exposure, measured in } \AA \text { of silver } \\
\text { chloride accumulated on silver sensors, from TIME = 0 to } \\
\text { TIME }=12 .\end{array}$ \\
\hline
\end{tabular}

Table A-6. Summary statistics for key weather variables in the different weather groupings.

\begin{tabular}{|c|c|c|c|c|c|c|c|}
\hline Grouping & $N=$ & $\begin{array}{c}\text { RH70 } \\
\text { Median } \dagger\end{array}$ & $\begin{array}{c}\text { RH80 } \\
\text { Median } †\end{array}$ & $\begin{array}{c}\text { RH90 } \\
\text { Median } \dagger\end{array}$ & $\begin{array}{c}\text { PRECIP } \\
\text { Median } \ddagger\end{array}$ & $\begin{array}{l}\text { CHLORIDE } \\
\text { Median * }\end{array}$ & $\begin{array}{l}\text { DATTYPE1 } \\
\text { Mean ** }\end{array}$ \\
\hline $\begin{array}{l}\text { None } \\
\text { (all data) }\end{array}$ & $160(100 \%)$ & 59.07 & 42.250 & 20.853 & 39.840 & 5,501 & $\begin{array}{l}0.4063 \\
(65 \text { sites using } \\
\text { new collection } \\
\text { method) }\end{array}$ \\
\hline 1 (“extreme”) & $22(14 \%)$ & 62.78 & 38.000 & 11.5000 & 31.495 & 24,147 & $\begin{array}{l}0.5455 \\
\text { (12 sites using } \\
\text { new collection } \\
\text { method) }\end{array}$ \\
\hline 2 (“wet”) & 47 (29\%) & 62.94 & 45.75 & 22.25 & 48.25 & 10,876 & \begin{tabular}{|l}
0.4043 \\
(19 sites using \\
new collection \\
method)
\end{tabular} \\
\hline 3 (“dry") & $91(57 \%)$ & 54.75 & 41.50 & 21.75 & 37.47 & 2,859 & \begin{tabular}{|l}
0.3736 \\
(34 sites using \\
new collection \\
method)
\end{tabular} \\
\hline \multicolumn{8}{|c|}{$\begin{array}{l}\text { † The RHx values represent the median percentage of time that the relative humidity exceeded } \mathrm{x} \% \text { from TIME }=0 \text { through } \\
\text { the end of the } 12^{\text {th }} \text { month (TIME }=12 \text { ). } \\
\text { ‡ Precipitation is measured in inches of rainfall. } \\
\text { * Chloride ion exposure is measured in Å of silver chloride accumulated on silver sensors. } \\
\text { ** DATTYPE takes the value zero (0) for those sites whose measurements were collected using an older method. DATTYE } \\
\text { takes the value one (1) for sites whose measurements were collected using a newer method. }\end{array}$} \\
\hline
\end{tabular}


Once the 160 sites having 12-month cumulative weather measurements were classified into one of three weather groupings, a linear discriminant rule was constructed, assuming proportional priors. The data in Table A-7 summarize the rule and may be used to classify new sites into one of the three weather groupings.

Table A-7. Linear discriminant functions developed from the three weather groupings.

\begin{tabular}{|c|c|c|c|c|}
\hline Grouping & Intercept & RH70 Coefficient & PRECIP Coefficient & CHLORIDE Coefficient \\
\hline $\begin{array}{c}1 \\
\text { ("extreme") }\end{array}$ & -27.53927 & 0.24527 & 0.01993 & 0.00125 \\
\hline $\begin{array}{c}2 \\
\text { ("wet") }\end{array}$ & -11.60465 & 0.20943 & 0.03930 & 0.00056 \\
\hline $\begin{array}{c}3 \\
\text { ("dry") }\end{array}$ & -6.02955 & 0.17848 & 0.02111 & 0.00022 \\
\hline
\end{tabular}

Given the relevant 12-month cumulative weather data (i.e., RH70, PRECIP, and CHLORIDE), a new site is classified into Group $\mathrm{j}$ if the linear discri function for Groupj is larger than either of the other two discriminant functions. For example, if the 12-month cumulative weather values for a new site are:

$$
\{\text { RH70 }=55.0, \text { PRECIP }=41.5, \text { CHLORIDE }=12,000\}
$$

then the three discriminant functions are:

Group 1: $-27.53927+0.24527(55.0)+0.01993(41.5)+0.00125(12000)=1.03329$

Group 2: $-11.60465+0.20943(55.0)+0.03930(41.5)+0.00056(12000)=8.26495$

Group 3: $-6.02955+0.17848(55.0)+0.02111(41.5)+0.00022(12000)=7.30292$

which implies that the new site would be classified into Group 2 since this discriminant function yields the largest value. Again, these distinctions will be transparent to the user of the software. The effect will be for the software to use the best algorithm to predict the response of the metalweather combination.

\section{A.3.2 Regression models for change in corrosion}

Table A-8 lists the amount of corrosion change data available for each type of metal, broken down by weather type and method of data collection (i.e., whether or not the data were collected using the older or newer methods listed at the bottom of Table A-2). 
Table A-8. Number of records corresponding to corrosion change for a given metal, by weather grouping and method of data collection.

\begin{tabular}{|c|c|c|c|c|c|c|c|c|c|}
\hline \multirow[b]{2}{*}{ Metal } & \multicolumn{3}{|c|}{ Weather Group 1 (“extreme”) } & \multicolumn{3}{|c|}{ Weather Group 2 (“wet”) } & \multicolumn{3}{|c|}{ Weather Group 3 (“dry”) } \\
\hline & All Data & $\begin{array}{l}\text { Older Data } \\
(\text { ID < 150) }\end{array}$ & $\begin{array}{c}\text { Newer Data } \\
(I D \geq 150)\end{array}$ & All Data & 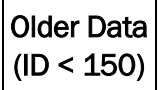 & $\begin{array}{c}\text { Newer Data } \\
(I D \geq 150)\end{array}$ & All Data & 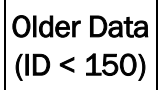 & $\begin{array}{c}\text { Newer Data } \\
(I D \geq 150)\end{array}$ \\
\hline AL2024 & 58 & $\mathrm{O}^{+}$ & 58 & 93 & $0^{+}$ & 93 & 172 & $\mathrm{O}^{\dagger}$ & 172 \\
\hline AL6061 $1^{\ddagger}$ & 113 & 50 & 63 & 223 & 130 & 93 & 448 & $271^{* *}$ & 177 \\
\hline AL7075 & 93 & 30 & 63 & 198 & 105 & 93 & 409 & 235 & 174 \\
\hline Steel & 88 & 30 & 58 & 207 & 114 & 93 & 414 & 245 & 169 \\
\hline Copper & 63 & 35 & $28^{*}$ & 124 & 70 & 54 & 324 & 195 & 129 \\
\hline $\begin{array}{l}\text { †Indicates th } \\
\text { ‡More data } \\
\text { *Fewest nur } \\
\text { **Most num }\end{array}$ & $\begin{array}{l}\text { the methoc } \\
\text { available } \mathrm{f} \\
\text { er of record } \\
\text { of records }\end{array}$ & $\begin{array}{l}\text { d of data collec } \\
\text { for AL6061, bo } \\
\text { ds in any cell in } \\
\text { in any cell in t }\end{array}$ & $\begin{array}{l}\text { ction cannot be } \\
\text { th overall and i } \\
\text { the table, amo } \\
\text { the table, amon }\end{array}$ & $\begin{array}{l}\text { used as a } \\
\text { in each sub } \\
\text { ng those st } \\
\text { g those suk }\end{array}$ & $\begin{array}{l}\text { regression cov } \\
\text { category, than } \\
\text { ubcategory cel } \\
\text { bcategory cells }\end{array}$ & $\begin{array}{l}\text { variate for AL2C } \\
n \text { for any other } \\
\text { Ills having nonz } \\
\text { s having nonzer }\end{array}$ & $\begin{array}{l}\text { 24. } \\
\text { metal. } \\
\text { ero counts. } \\
\text { ro counts. }\end{array}$ & & \\
\hline
\end{tabular}

Following the regression modeling strategy described in Harrell, it is desirable that the linear models that are developed not exhibit over-fitting or regression to the mean. From the guidelines in this text, it was determined that each regression model should consume no more than approximately 10 degrees of freedom. Ideally each model should also have the same structure so that differences between metals and weather groupings with respect to corrosion can be more easily determined.

\section{A.3.2.1 Assessment of data collection method}

The first step in the model-building process was to determine the statistical significance of DATTYPE1. If this concomitant variable is statistically significant, it implies that the method of data collection significantly impacts the measured corrosion levels, an undesirable result. Weather Groups 2 and 3 had the most sites where the data collection was performed using the newer method (19 and 34, respectively) and AL6061 data are the most abundant of any metal. Any significant impact from DATTYPE1 with respect to R2 is most likely to be seen with these AL6061 data.

Therefore, an initial set of models for corrosion change in AL6061 for Weather Groups 2 and 3 was built. One set of models included RH70CHG, PRECIPCHG, CHLORIDECHG, CORROSION_LAG, and all possible twoway interactions between RH70CHG, PRECIPCHG, CHLORIDECHG, and CORROSION_LAG, for a total of 10 degrees of freedom each. Another set of models included the same predictor variables, with the addition of DATTYPE1, for a total of 11 degrees of freedom each. 
The adjusted R2 for the AL6061 models excluding DATTYPE1, and associated with Weather Groups 2 and 3, were $72.9 \%$ and $72.4 \%$, respectively. The adjusted R2 for the AL6061 models including DATTYPE1, and associated with Weather Groups 2 and 3, were $75.1 \%$ and 74.1\%, respectively. The increase in R2 due to the inclusion of DATTYPE1 is marginal; therefore, DATTYPE1 was dropped from further consideration in all model building for all metals.

\section{A.3.2.2 Variable selection}

The base model used in Section 3.2.1 to evaluate the influence of the method of data collection may include variables that do not contribute important information to the understanding of corrosion change, and may exclude important predictors. Therefore, the following variable selection method was adopted:

1. Approximately 10 total degrees of freedom will be allocated to each model, and the structure of the models will be the same.

2. Initial models for all metals except AL2024, and only for Weather Groups 2 and 3, will include the variables RH70CHG, PRECIPCHG, CHLORIDECHG, CORROSION_LAG, and all possible two-, three, and four-way interactions between them. These models will be used to determine theinteraction terms that should be kept in the final set of models used for all metals and all weather groups. There are a total of eight initial models.

3. When a choice exists, preference is given to interaction terms of lesser order.

4. Two-, three and four-way interaction terms will only be kept if they are statistically significant at $\alpha=0.10$ across at least three of the eight models being considered

5. All main effects involving RH70CHG, PRECIPCHG, CHLORIDECHG, and CORROSION_LAG will be kept no matter what.

Application of this methodology yielded the eight concomitant variables to be used in all the models for corrosion change listed in Table A-9. 
Table A-9. Concomitant variables (including interaction terms) selected for use in all regression models.

\begin{tabular}{|l|}
\hline Variable Name \\
\hline CHLORIDECHG \\
\hline CORROSION_LAG \\
\hline PRECIPCHG \\
\hline RH7OCHG \\
\hline RH7OCHG : CHLORIDECHG \\
\hline RH7OCHG : CORROSION_LAG \\
\hline RH7OCHG : CHLORIDECHG : PRECIPCHG \\
\hline RH7OCHG : CHLORIDECHG : CORROSION_LAG : PRECIPCHG \\
\hline
\end{tabular}

\section{A.3.2.3 Modeling results}

The response variable CORRCHG (for a definition, see Table A-2) was regressed on the concomitant variables given in Table A-9, for each metal and weather group. This yielded a total of 15 regression models, which are described in Appendix D. From this appendix, the regression coefficients, t-tests, adjusted R2, and other model details may be found. Table A-10 describes the properties of these models. From this table, it is seen that 11 of the 15 models have excellent adjusted R2 values (greater than $72.3 \%$ in all cases). The predominance of the good explanatory power of the variables in Table A-9 suggests that the variable selection method described in Section 3.2.2 worked.

In the process of forecasting the total corrosion at the end of time $\mathrm{k}$, the forecasted total corrosion at the end of time $\mathrm{k}-1$ is treated as fixed and substituted for CORROSION_LAG in the regression models. This has the effect of producing prediction intervals that are narrower than nominal.

Table A-10. Summary of regression model characteristics.

\begin{tabular}{|c|c|c|c|c|c|c|c|c|c|}
\hline \multirow[b]{2}{*}{$\begin{array}{l}\text { Metal } \\
\text { Model }\end{array}$} & \multicolumn{3}{|c|}{ Weather Group 1 (“extreme”) } & \multicolumn{3}{|c|}{ Weather Group 2 (“wet”) } & \multicolumn{3}{|c|}{ Weather Group 3 (“dry”) } \\
\hline & $\mathrm{R}^{2}$ & $\begin{array}{c}\text { Adjusted } \\
\mathrm{R}^{2}\end{array}$ & p-value & $\mathrm{R}^{2}$ & $\begin{array}{c}\text { Adjusted } \\
\mathrm{R}^{2}\end{array}$ & p-value & $\mathrm{R}^{2}$ & $\begin{array}{c}\text { Adjusted } \\
\mathrm{R}^{2}\end{array}$ & p-value \\
\hline AL2024 & $59.3 \%$ & $50.9 \%$ & $<0.0001$ & $78.5 \%$ & $75.9 \%$ & $<0.0001$ & $52.1 \%$ & $49.2 \%$ & $<0.0001$ \\
\hline AL6061 & $78.8 \%$ & $76.8 \%$ & $<0.0001$ & $74.5 \%$ & $73.3 \%$ & $<0.0001$ & $72.9 \%$ & $72.3 \%$ & $<0.0001$ \\
\hline AL7075 & $79.6 \%$ & $77.1 \%$ & $<0.0001$ & $54.1 \%$ & $51.6 \%$ & $<0.0001$ & $52.5 \%$ & $51.3 \%$ & $<0.0001$ \\
\hline Steel & $83.5 \%$ & $81.4 \%$ & $<0.0001$ & $75.4 \%$ & $74.2 \%$ & $<0.0001$ & $73.5 \%$ & $72.8 \%$ & $<0.0001$ \\
\hline Copper & $83.4 \%$ & $80.4 \%$ & $<0.0001$ & $75.6 \%$ & $73.4 \%$ & $<0.0001$ & $75.6 \%$ & $74.8 \%$ & $<0.0001$ \\
\hline
\end{tabular}




\section{A.4 Conclusions}

The regression models for corrosion change were successfully used to build forecasts for total corrosion, over time, for five types of bare metal coupons over three distinct types of cumulative weather. There were a total of 15 different regression models, each using the same set of predictor variables.

This methodology is inherently an approximation to a true repeatedmeasures statistical model. Furthermore, the regression methodology adopted in this analysis (and the previous analysis from 2003) explicitly assumed that the amount of corrosion change was linearly related not only to the weather exposure in a particular time interval, but also to the previous time interval's cumulative corrosion levels.

Table A-11 lists the \%relative error in predicted cumulative corrosion levels versus actual cumulative corrosion levels. The formula used to compute \%relative error is:

$\frac{\text { Actual Cumulative Corrosion - Predicted Cumulative Corrosion }}{\text { Actual Cumulative Corrosion }} * 100$

Therefore, negative values listed in Table A- 11 imply that the predicted cumulative corrosion levels generally exceed the actual cumulative corrosion levels. Positive values in Table A-11 have the opposite interpretation.

Inspection of the data in Table A-11 clarifies that there is generally a systematic bias such that predicted values at early time points ( 3 or 6 months) are generally less than the measured cumulative corrosion values. It is also clear that, at later time points ( 9 or 12 months), there is a systematic bias such that predicted cumulative corrosion values are generally larger than the measured cumulative corrosion values. Those models having higher adjusted R2 values tended to perform better than those having smaller adjusted R2 values; nevertheless, with the exception of AL7075 in the "extreme" weather environment, the described systematic bias is apparent.

The appearance of a systematic bias calls into question the optimality of the assumption that corrosion change is linearly related to the predictor variables that are available. This suggests that future corrosion modeling efforts be undertaken to determine what, if any, nonlinear relationships exist between corrosion change and the available predictor variables (i.e., 
CORROSION_LAG, RH70CHG, etc.). Exponential models may be indicated as a first step in any such effort.

Despite the appearance of biases in the predicted cumulative corrosion levels, the models developed in this work should continue to be useful. A comparison of the actual cumulative corrosion levels to the $95 \%$ prediction intervals associated with the models demonstrates that the actual cumulative corrosion levels are contained within them $83.7 \%$ of the time. This is very similar to the results obtained in 2003, and therefore represents a moderate and historically tolerable departure from the nominal 95\%. Furthermore, the models developed in this work are better capable of handling a wider variety of weather patterns and types of metal. (No models had previously been developed for AL2024.)

Table A-11. Median \% relative error of predictions from the regression models

\begin{tabular}{|c|c|c|c|}
\hline & $\begin{array}{l}\text { Weather Group } 1 \\
\text { ("extreme") }\end{array}$ & $\begin{array}{l}\text { Weather Group } 2 \\
\text { ("wet”) }\end{array}$ & $\begin{array}{c}\text { Weather Group } 3 \\
\text { (“dry”) }\end{array}$ \\
\hline Metal Model & $\begin{array}{c}\text { \%Relative Error } \\
(\mathrm{TIME}=3,6,9,12)\end{array}$ & $\begin{array}{c}\text { \%Relative Error } \\
(\mathrm{TIME}=3,6,9,12)\end{array}$ & $\begin{array}{c}\text { \%Relative Error } \\
(\mathrm{TIME}=3,6,9,12)\end{array}$ \\
\hline AL2024 & $(-49 \%,-29 \%,-19 \%,-13 \%)^{\dagger}$ & $(17 \%,-3 \%,-6 \%,-38 \%)$ & $(22 \%,-1 \%,-10 \%,-14 \%)^{\dagger}$ \\
\hline AL6061 & $(20 \%, 10 \%, 1 \%,-1 \%)$ & $(20 \%, 7 \%,-8 \%,-14 \%)$ & $(18 \%,-2 \%,-9 \%,-9 \%)$ \\
\hline AL7075 & $(-7 \%, 8 \%, 4 \%, 12 \%)$ & $\begin{array}{c}(14 \%,-19 \%,-42 \%,- \\
42 \%)^{\dagger}\end{array}$ & $(23 \%, 7 \%,-6 \%,-26 \%)^{\dagger}$ \\
\hline Steel & $(9 \%,-1 \%,-1 \%,-13 \%)$ & $(33 \%, 16 \%, 3 \%,-20 \%)$ & $(17 \%, 8 \%,-2 \%,-11 \%)$ \\
\hline Copper & $(11 \%, 4 \%,-1 \%,-8 \%)$ & $(20 \%,-3 \%,-10 \%,-19 \%)$ & $(45 \%, 14 \%,-35 \%,-45 \%)$ \\
\hline
\end{tabular}




\section{Appendix B: Data Processing}

\section{B.1 Modifications prior to data merging}

The file "qry_BaseResponsealldata_rev307.txt" was modified according to the following list of changes and saved as "Response.txt":

1. Deleted all records corresponding to AL2024 or missing corrosion levels.

2. Set the predicted, upper bound, and lower bound corrosion values to 0 at time $=0$.

3. Dropped HISTORYID, STARTDATE.

4. Renamed several variables:

a. $\mathrm{BASENAME}=\mathrm{AFBASE}$

b. RECORDDATEMONTH $=$ MONTH

c. RECORDDATEYEAR =YEAR

d. QUARTERINSEQUENCE $=$ TIME.

The file "qry_BaseExplanatory_alldata.txt" was modified according to the following list of changes and saved as "Explanatory.txt":

1. Dropped HISTORYID.

2. Renamed several variables:

a. ASSIGNEDID =ID

b. RECORDDATEYEAR $=$ YEAR

c. CHLORINE $=$ CHLORIDE

d. $\mathrm{BASENAME}=\mathrm{AFBASE}$

e. RECORDDATEMONTH $=$ MONTH.

The file "All_AL2024_Data_1207.txt" was modified according to the following list of changes and saved as "AL2024.txt":

1. Dropped BASE, START, RECORDDATEMONTH, RECORDDATEYEAR, MONTH, YEAR, STARTDATE.

2. Renamed several variables:

a. $\mathrm{BASENAME}=\mathrm{AFBASE}$

b. QUARTERINSEQUENCE $=$ TIME

c. $A S S I G N E D I D=I D$.

3. Converted the inputted Base ID numbers from the default character format to a numeric format. 


\section{B.2 Merging the data, and modifications after data merging}

First, the Response.txt and Explanatory.txt datasets were merged according to unique combinations of AFBASE, YEAR, MONTH. The resultant dataset was then modified according to the following list of changes and saved as "Corrosion.txt":

1. Dropped observations where the METAL variable was missing.

2. Fixed a variety of METAL labeling mistakes:
a. "AL6062" changed to "AL6061"
b. "Copper" changed to "Cu"
c. "AL7076" changed to "AL7075."

3. Added the AL2024.txt records to the Corrosion.txt data - this is the first point at which the variables in the AL2024.txt data match up with the variables in Corrosion.txt.

4. For those records where MONTH, YEAR are available (i.e., for nonAL2024 records), created a unifying DATE variable.

5. Modified the data to make sure that at time $=0$, all of the weather variables (RH70, RH80, RH90, PRECIP, CHLORIDE) are also 0.

6. Ensured that the Base ID variable was well-defined across all reconds for a given Base, when the ID existed. This consistency was not necessarily found in the raw data.

7. Some of the Bases did not have an ID. The following were fixed:
a. "Wheeler (229)" $\rightarrow$ ID $=229$
b. "Whidbey (230)" $\rightarrow \mathrm{ID}=230$
c. "Williamtown02 (132)" $\rightarrow$ ID $=132$
d. "Winnipeg (231)" $\rightarrow$ ID $=231$
e. "Amberley02 (103)" $\rightarrow$ ID = 103
f. "Knoxville (198)" $\rightarrow$ ID = 198 .

8. Created an indicator variable to denote observations that were collected using a "new" method vs. the older method in the original database: a. Base ID > $150 \rightarrow$ "New Method," otherwise $\rightarrow$ "Old Method."

9. There were a handful of sites that had only one record for a given metal. These records were dropped since they are not helpful in model building.

The Corrosion.txt data were saved as "Corrosion.xls" and sent to Bill Abbot for examination. Two problems surfaced: some of the TIME variables did not match up with the DATE variable ordering, and some sites had missing weather data for one or more types of metal. This initiated a back-andforth process taking several weeks. The final result of this iterative data- 
cleaning was the new MS Excel file "Corrosion3.xls." This file was then subjected to the following modifications and saved as "Corrosion3.txt":

1. There were a few sites that had duplicate records for the same METAL and DATE (but possibly different corrosion values). These duplicates were eliminated by creating a single record whose corrosion value corresponded to the mean of the corrosion values in the duplicate records.

2. A few of the corrosion values were not strictly non-decreasing, meaning that the measured corrosion levels in successive time periods would actually decrease. As this is nonsensical, these records were fixed using the following logic:

a. If AFBASE = "Daytona 75 (180)" and METAL = "AL2024" and TIME $=$ $12 \rightarrow$ CORROSION $=6159$

b. If AFBASE $=$ “KSC 1/ 4 (199)" and METAL $=$ "AL7075" and TIME $=6$ $\rightarrow$ CORROSION $=1475$

c. If AFBASE = “KSC 1/ 4 (199)" and METAL = “AL7075" and TIME $=9$ $\rightarrow$ CORROSION $=1657$

d. If AFBASE = “West J efferson (227)" and METAL = "AL7075” and TIME $=3 \rightarrow$ CORROSION $=52$

e. If AFBASE = "MSP 02 (124)" and METAL $=$ "Steel" and TIME $=9 \rightarrow$ CORROSION $=7969$.

3. Renamed several variables to indicate the fact that they correspond strictly to the weather exposure of the metals in a particular time interval (i.e., do NOT represent cumulative weather exposure levels):
a. $\mathrm{RH} 70=\mathrm{RH} 70 \mathrm{CHG}$
b. $\mathrm{RH} 80=\mathrm{RH} 80 \mathrm{CHG}$
c. $\mathrm{RH} 90=\mathrm{RH} 90 \mathrm{CHG}$
d. $\mathrm{PRECIP}=\mathrm{PRECIPCHG}$.

4. Created several variables:

a. CORROSION_LAG - This is the cumulative corrosion in the previous time period.

b. CORRCHG - The change in corrosion from previous time period to the end of the current time period.

c. TIME_LAG - The cumulative time of exposure up through the previous time period.

d. TIMECHG - The change in cumulative time from the previous period to the end of the current period, i.e., how long the current period is.

e. CHLORIDE_LAG - The cumulative chloride exposure through the end of the previous time period.

f. CHLORIDECHG - The chloride exposure only in the current time period. 
g. RH70, RH80, RH90 - These are the CUMULATIVE percentages of time where the relative humidity has exceeded $70 \%, 80 \%$, and $90 \%$. These values take into account the length of time from time $=0$ to the end of the current period.

h. PRECIP - Cumulative precipitation to the end of the current period. 


\section{Appendix C: Plots of Partitioning Around Medoids Clustering}

Based on the graphical representations of the two, three, and four cluster solutions (Figures C-1, C-2, and C-3), the $\mathrm{k}=3$ cluster solution is clearly better. The $\mathrm{k}=2$ cluster solution shows that Group 1 has a great many sites that are poorly classified (the negative silhouette width values on the left side of the graph). These sites do not classify easily into either Group 1 or 2 . The $\mathrm{k}=4$ solution shows that one of the groups only has two sites: Group 4. It is difficult to imagine defining a weather cluster on the basis of only two observed sites, and this solution is therefore not recommended.

The $\mathrm{k}=3$ solution demonstrates excellent properties. There are a reasonable number of sites classed into each weather grouping - Groups 1, 2, and 3 have 22,47 , and 91 sites, respectively. The average silhouette width is 0.65 , implying that there are sharp distinctions between the weather groups with respect to 12-month weather averages. Finally, there is little to suggest that sites are being improperly classified as evidenced by the virtual lack of negative silhouette values. Table A- 6 summarizes the cumulative weather variables for these three groupings. 
Figure C-1. Average silhouette width and sample sizes for $\mathrm{k}=2$ clusters.

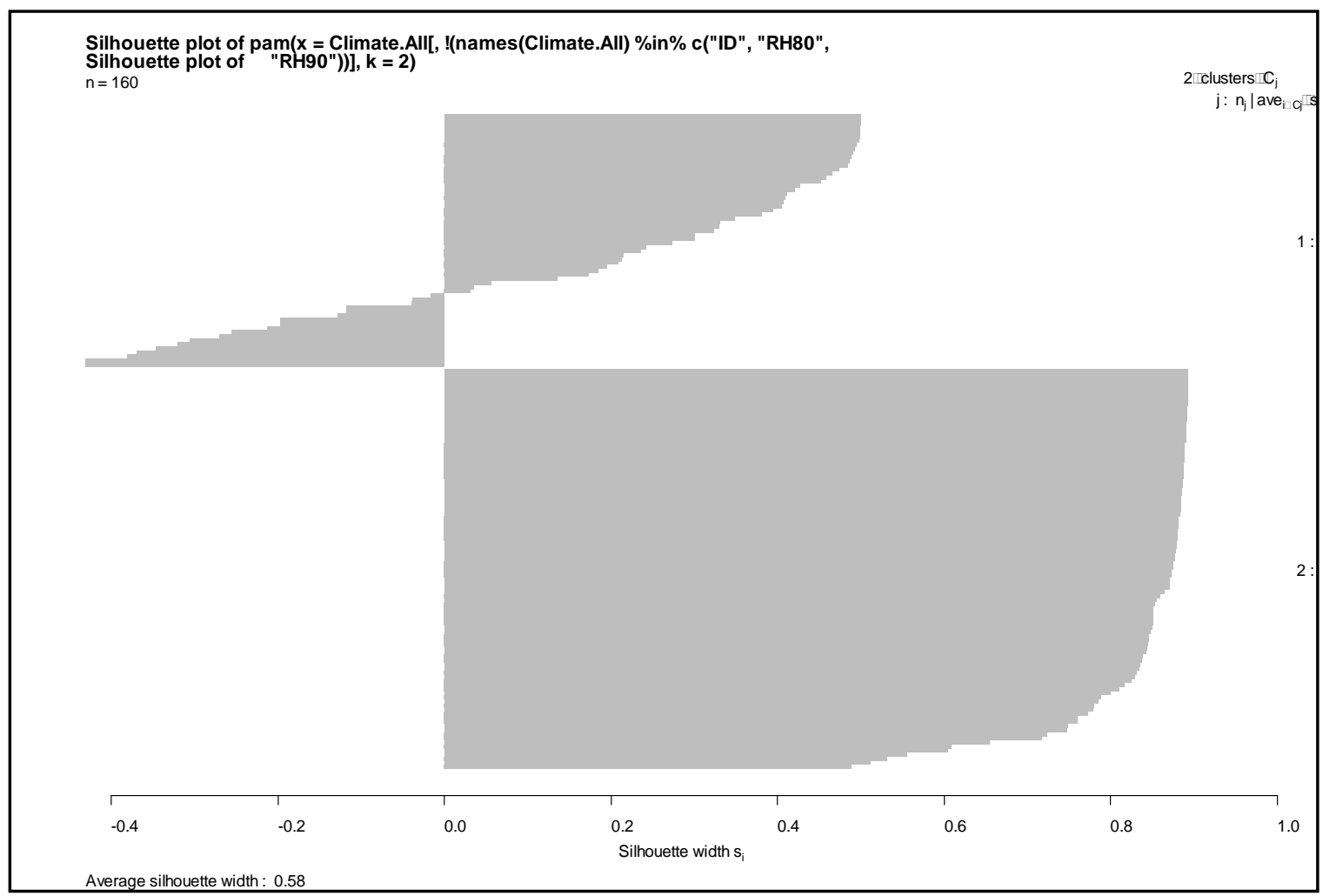

Figure C-2. Average silhouette width and sample sizes for $\mathrm{k}=3$ clusters.

Silhouette plot of pam(x = Climate.All[, !(names(Climate.All) \%in\% c("ID", "RH80",

Silhouette plot of "RH90"))], $\mathrm{k}=3$ )

$\mathrm{n}=160$

3 clusters $\mathrm{C}_{\mathrm{j}}$

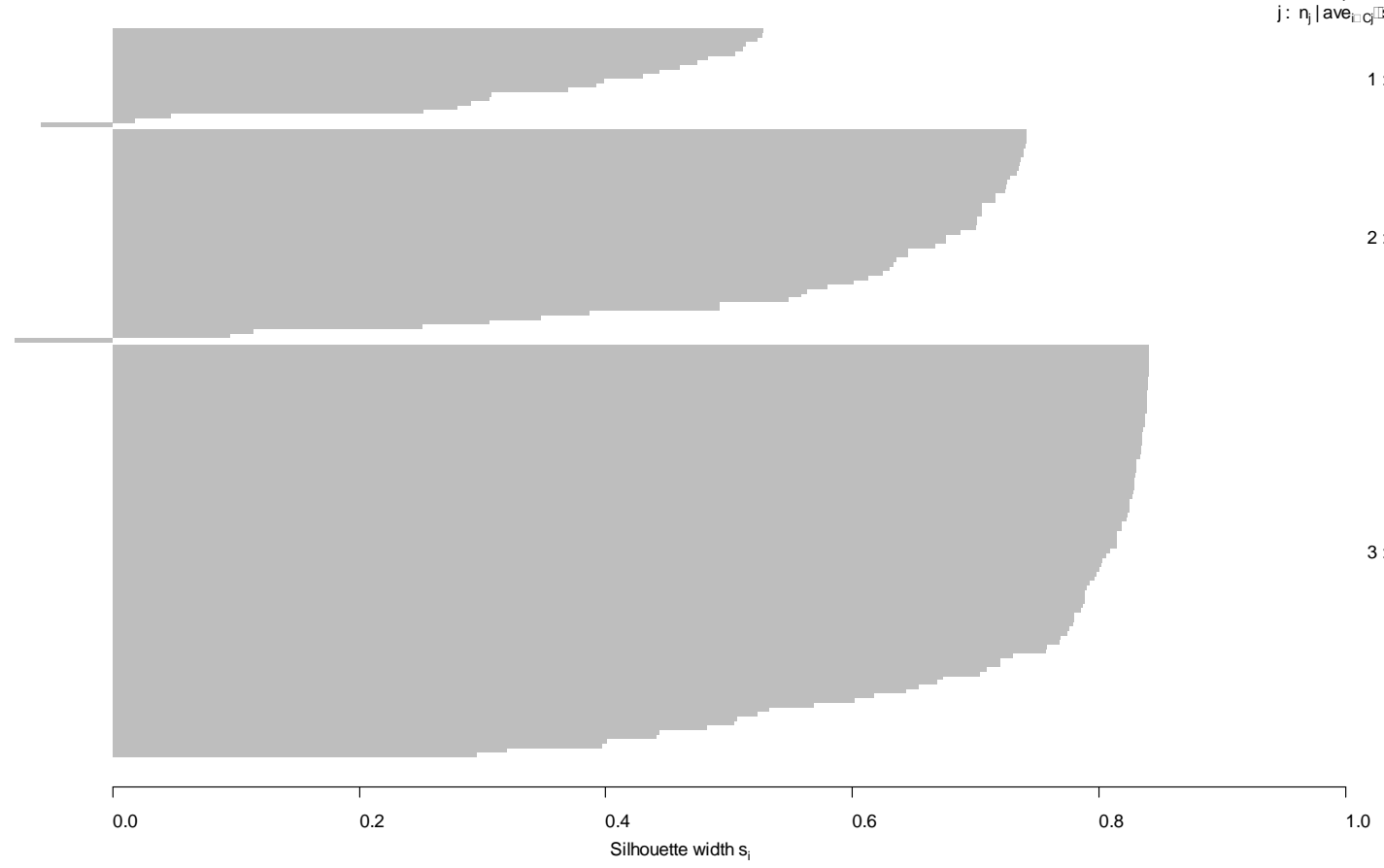


Figure C-3. Average silhouette width and sample sizes for $k=4$ clusters.

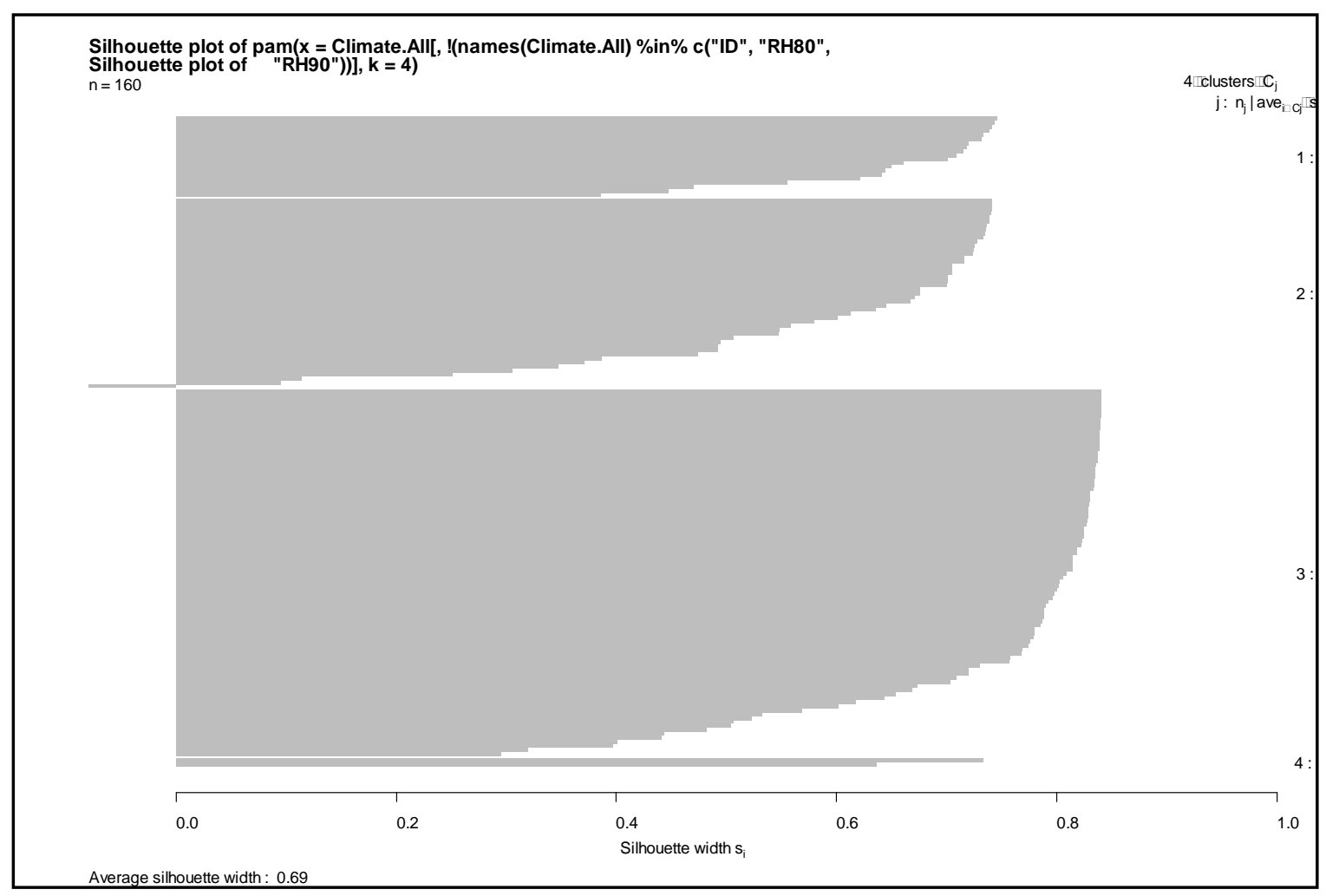




\section{Appendix D: Regression Models}

This appendix details the code used in the creation of the model.

\section{D.1 Linear models for CORRCHG in AL2024}

\section{D.1.1 "Extreme" weather model (Group 1)}

$>\operatorname{summary}(A L 2024 \cdot g p 1 \cdot \operatorname{lm} 1)$

Call:

$\operatorname{lm}$ (formula $=$ CORRCHG $\sim$ CORROSION_LAG + RH7OCHG + PRECIPCHG + CHLORIDECHG + CORROSION_LAG:RH7OCHG + H7OCHG:CHLORIDECHG + RH70CHG : PRECIPCHG : CHLORIDECHG + CORROSION_LAG:RH7OCHG:PRECIPCHG:CHLORIDECHG - 1, data = Corrosion.Data2 [Corrosion.Data2\$Metal == "AL2024" \& Corrosion. Data2\$Group == 1, ])

Residuals:

Min 1Q Median 3Q Max

$-1261.9-183.4-38.172 .3 \quad 3046.9$

Coefficients:

Estimate Std. Error $t$ value $\operatorname{Pr}(>|t|)$

CORROSION_LAG $-5.36 \mathrm{e}-01 \quad 4.25 \mathrm{e}-01-1.26 \quad 0.215$

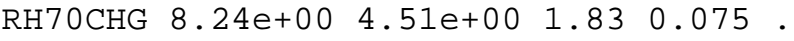

PRECIPCHG $-1.53 e+01 \quad 3.80 \mathrm{e}+01-0.40 \quad 0.690$

CHLORIDECHG 4.54e-03 2.23e-02 $0.20 \quad 0.840$

CORROSION_LAG:RH7OCHG 9.81e-03 6.44e-03 1.520 .136

RH70CHG : CHLORIDECHG 7.34e-05 7.26e-04 $0.10 \quad 0.920$

RH70CHG:PRECIPCHG:CHLORIDECHG 4.53e-05 8.23e-05 ๑.55 ०.585

CORROSION_LAG:RH7OCHG:PRECIPCHG :CHLORIDECHG - $2.85 \mathrm{e}-081.96 \mathrm{e}-08$ $1.46 \quad 0.153$

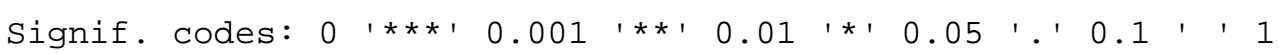


Residual standard error: 593 on 39 degrees of freedom

Multiple R-Squared: $\odot .593$, Adjusted R-squared: 0.509

F-statistic: 7.1 on 8 and 39 DF, p-value: $9.35 \mathrm{e}-06$

\section{D.1.2 “Wet” weather model (Group 2)}

$>\operatorname{summary}(\mathrm{AL2024.gp2.Im1)}$

Call:

$1 \mathrm{~m}$ (formula $=$ CORRCHG $\sim$ CORROSION_LAG + RH7OCHG + PRECIPCHG + CHLORIDECHG + CORROSION_LAG:RH7OCHG + RH7OCHG:CHLORIDECHG + RH7OCHG:PRECIPCHG:CHLORIDECHG + CORROSION_LAG:RH7OCHG:PRECIPCHG:CHLORIDECHG - 1, data = Corrosion.Data2 [Corrosion.Data2\$Metal == "AL2024" \& Corrosion. Data2\$Group == 2, ])

Residuals:

Min 1Q Median 3Q Max

$-565.9-129.2-34.431 .9991 .2$

Coefficients:

Estimate Std. Error $t$ value $\operatorname{Pr}(>|t|)$

CORROSION_LAG $-7.21 \mathrm{e}-02 \quad 1.94 \mathrm{e}-01 \quad-0.37 \quad 0.7109$

RH7๑CHG $4.63 \mathrm{e}+0 \odot \quad 1.74 \mathrm{e}+0 \odot \quad 2.660 .0098$ **

PRECIPCHG $-9.58 \mathrm{e}+0 \odot \quad 1.12 \mathrm{e}+01-0.86 \quad 0.3946$

CHLORIDECHG 2.09e-02 2.85e-02 $0.74 \quad 0.4649$

CORROSION_LAG:RH70CHG $7.77 \mathrm{e}-03 \quad 2.48 \mathrm{e}-03 \quad 3.140 .0025$ * *

RH70CHG:CHLORIDECHG $-1.60 \mathrm{e}-03 \quad 8.58 \mathrm{e}-04 \quad-1.86 \quad 0.0674$.

RH70CHG:PRECIPCHG:CHLORIDECHG 1.09e-04 5.69e-05 1.91 0.0600.

CORROSION_LAG:RH7OCHG:PRECIPCHG:CHLORIDECHG -5.๑8e-๑8 2.74e-๑8 1.850 .0684 .

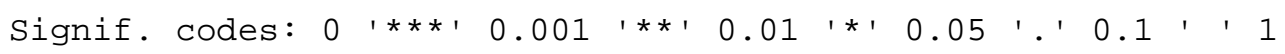

Residual standard error: 254 on 67 degrees of freedom

Multiple R-Squared: 0.785 , Adjusted R-squared: 0.759 
F-statistic: 30.5 on 8 and 67 DF, p-value: $<2 e-16$

\section{D.1.3 "Dry" weather model (Group 3)}

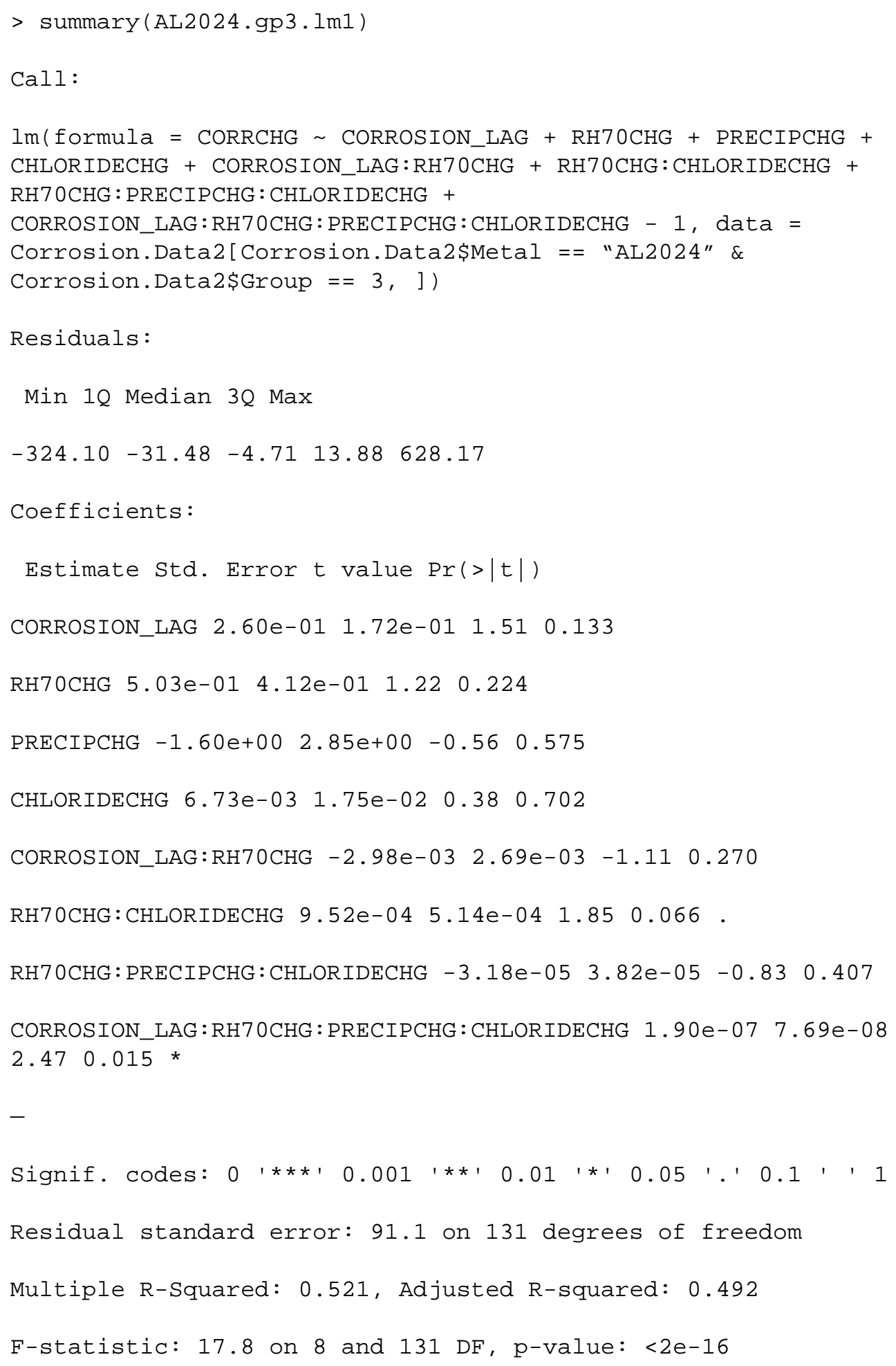




\section{D.2 Linear models for CORRCHG in AL6061}

\section{D.2.1 “Extreme" weather model (Group 1)}

$>\operatorname{summary}($ AL6061.gp1.1m2)

Call:

$\operatorname{lm}$ (formula $=$ CORRCHG $\sim$ CORROSION_LAG + RH7OCHG + PRECIPCHG + CHLORIDECHG + CORROSION_LAG:RH7OCHG + RH7OCHG:CHLORIDECHG + RH7OCHG : PRECIPCHG:CHLORIDECHG + CORROSION_LAG:RH7OCHG:PRECIPCHG:CHLORIDECHG - 1, data = Corrosion.Data2 [Corrosion.Data2\$Metal == "AL6061" \&

Corrosion. Data2\$Group == 1, ])

Residuals:

Min 1Q Median 3Q Max

$\begin{array}{llllll}-128.87 & -42.50 & -5.69 & 31.29 & 169.29\end{array}$

Coefficients:

Estimate Std. Error $t$ value $\operatorname{Pr}(>|t|)$

CORROSION_LAG $7.49 \mathrm{e}-02 \quad 1.73 \mathrm{e}-010.430 .667$

RH70CHG 8.52e-01 3.14e-01 2.72 0.008 **

PRECIPCHG $2.15 \mathrm{e}+00 \quad 1.53 \mathrm{e}+00 \quad 1.410 .163$

CHLORIDECHG $-2.29 \mathrm{e}-04 \quad 2.38 \mathrm{e}-03 \quad-0.10 \quad 0.924$

CORROSION_LAG:RH70CHG $4.39 \mathrm{e}-04 \quad 2.93 \mathrm{e}-03 \quad 0.15 \quad \odot .881$

RH70CHG:CHLORIDECHG $1.37 \mathrm{e}-04 \quad 5.74 \mathrm{e}-05 \quad 2.390 .019$ *

RH70CHG:PRECIPCHG:CHLORIDECHG $-9.37 \mathrm{e}-06 \quad 4.66 \mathrm{e}-06 \quad-2.01 \quad 0.048$ * CORROSION_LAG:RH7OCHG:PRECIPCHG:CHLORIDECHG 2.76e-09 $1.41 \mathrm{e}-08$ 0.200 .845

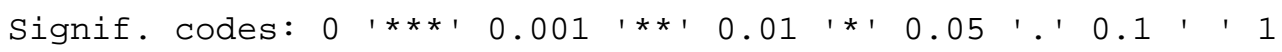
Residual standard error: 60.9 on 83 degrees of freedom Multiple R-Squared: 0.788 , Adjusted R-squared: 0.768 F-statistic: 38.6 on 8 and 83 DF, p-value: $<2 e-16$ 


\section{D.2.2 "Wet" weather model (Group 2)}

$>\operatorname{summary}($ AL6061.gp2.1m2)

Call:

$\operatorname{lm}($ formula $=$ CORRCHG $\sim$ CORROSION_LAG + RH7OCHG + PRECIPCHG + CHLORIDECHG + CORROSION_LAG:RH7OCHG + RH7OCHG:CHLORIDECHG + RH7OCHG:PRECIPCHG:CHLORIDECHG + CORROSION_LAG:RH7OCHG:PRECIPCHG:CHLORIDECHG - 1, data = Corrosion.Data2 [Corrosion.Data2\$Metal == "AL6061" \& Corrosion. Data2\$Group $==2$,$] )$

Residuals:

Min 1Q Median 3Q Max

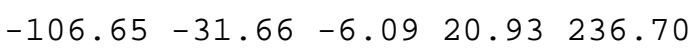

Coefficients:

Estimate std. Error $t$ value $\operatorname{Pr}(>|t|)$

CORROSION_LAG $-6.02 \mathrm{e}-02 \quad 1.14 \mathrm{e}-01-0.53 \quad 0.599$

RH70CHG 8.82e-01 2.21e-01 3.99 9.8e-05***

PRECIPCHG $-6.28 \mathrm{e}-01 \quad 8.53 e-01-0.74 \quad 0.462$

CHLORIDECHG $1.02 \mathrm{e}-02 \quad 4.98 \mathrm{e}-03 \quad 2.050 .042$ *

CORROSION_LAG:RH7OCHG 3.13e-03 $1.63 \mathrm{e}-031.930 .056$.

RH70CHG:CHLORIDECHG $-6.18 \mathrm{e}-05 \quad 1.11 \mathrm{e}-\odot 4-0.56 \quad 0.579$

RH70CHG:PRECIPCHG:CHLORIDECHG $1.68 \mathrm{e}-06 \quad 3.45 \mathrm{e}-06 \quad 0.49 \quad 0.627$

CORROSION_LAG:RH7OCHG:PRECIPCHG:CHLORIDECHG $-1.41 \mathrm{e}-081.32 \mathrm{e}-08-$ 1.070 .286

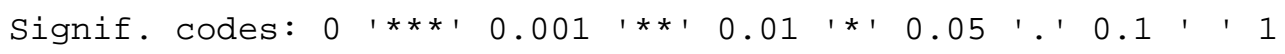

Residual standard error: 52 on 171 degrees of freedom

Multiple R-Squared: 0.745 , Adjusted R-squared: 0.733

F-statistic: 62.5 on 8 and 171 DF, p-value: $<2 e-16$

\section{D.2.3 "Dry" weather model (Group 3)}

$>\operatorname{summary}($ AL6061.gp3.Im2) 
Call:

$\operatorname{lm}($ formula $=$ CORRCHG $\sim$ CORROSION_LAG + RH7OCHG + PRECIPCHG + CHLORIDECHG + CORROSION_LAG:RH7OCHG + RH7OCHG:CHLORIDECHG + RH7OCHG : PRECIPCHG: CHLORIDECHG + CORROSION_LAG:RH7OCHG:PRECIPCHG:CHLORIDECHG - 1, data = Corrosion.Data2 [Corrosion.Data2\$Metal == "AL6061" \& Corrosion. Data2\$Group $==3$,$] )$

Residuals:

Min 1Q Median 3Q Max $\begin{array}{lllll}-45.75 & -14.31 & -0.63 & 12.57 & 95.47\end{array}$

Coefficients:

Estimate Std. Error $t$ value $\operatorname{Pr}(>|t|)$

CORROSION_LAG 2.66e-01 5.19e-02 5.12 5.0e-07 ***

RH70CHG $3.78 \mathrm{e}-015.41 \mathrm{e}-027.001 .3 \mathrm{e}-11$ ***

PRECIPCHG $1.31 \mathrm{e}-01 \quad 2.74 \mathrm{e}-01 \quad 0.48 \quad 0.632$

CHLORIDECHG $3.63 \mathrm{e}-03 \quad 3.11 \mathrm{e}-03 \quad 1.17 \quad 0.244$

CORROSION_LAG:RH7OCHG $-4.33 e-03 \quad 9.78 e-04-4.421 .3 e-05 * * *$

RH70CHG:CHLORIDECHG $1.86 \mathrm{e}-04 \quad 8.15 \mathrm{e}-05 \quad 2.280 .023$ *

RH70CHG:PRECIPCHG:CHLORIDECHG $-6.22 \mathrm{e}-06 \quad 5.81 \mathrm{e}-06 \quad-1.07 \quad 0.285$

CORROSION_LAG:RH7OCHG:PRECIPCHG:CHLORIDECHG 2.98e-08 3.95e-08 0.760 .450

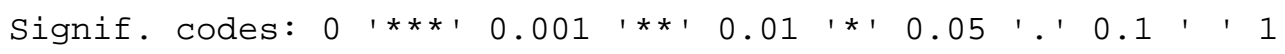
Residual standard error: 20.4 on 350 degrees of freedom

Multiple R-Squared: 0.729 , Adjusted R-squared: 0.723

F-statistic: 118 on 8 and 350 DF, p-value: <2e-16

\section{D.3 Linear models for CORRCHG in AL7075}

\section{D.3.1 “Extreme" weather model (Group 1)}

$>\operatorname{summary}(\mathrm{AL7075.gp1.1m1)}$

Call: 


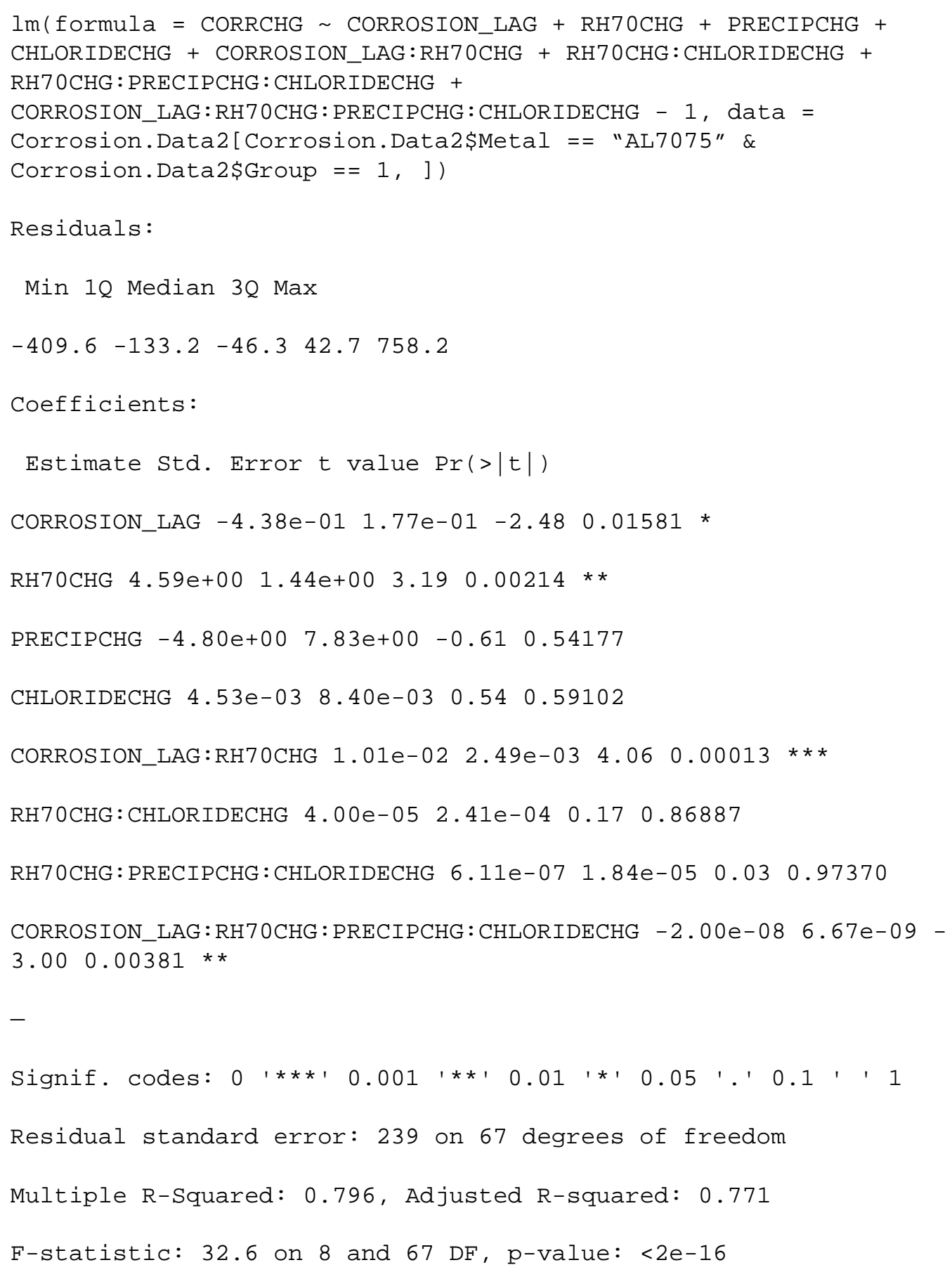

\section{D.3.2 "Wet" weather model (Group 2)}

$>\operatorname{summary}(A L 7075 \cdot g p 2 \cdot \operatorname{lm} 1)$

Call:

$1 \mathrm{~m}$ (formula $=$ CORRCHG $\sim$ CORROSION_LAG + RH7OCHG + PRECIPCHG + CHLORIDECHG + CORROSION_LAG:RH7OCHG + RH7OCHG:CHLORIDECHG + RH7OCHG:PRECIPCHG:CHLORIDECHG + 
CORROSION_LAG:RH7OCHG:PRECIPCHG:CHLORIDECHG - 1, data = Corrosion.Data2 [Corrosion.Data2\$Metal == "AL7075" \&

Corrosion. Data2 $\$$ Group $==2$,$] )$

Residuals:

Min 1Q Median 3Q Max

$-504.3-117.1-50.016 .51558 .5$

Coefficients:

Estimate Std. Error $t$ value $\operatorname{Pr}(>|t|)$

CORROSION_LAG $2.67 \mathrm{e}-01 \quad 1.72 \mathrm{e}-01 \quad 1.560 .122$

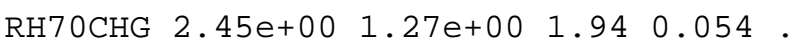

PRECIPCHG $3.43 \mathrm{e}-01 \quad 6.09 \mathrm{e}+0 \odot \quad 0.06 \quad 0.955$

CHLORIDECHG $4.43 e-03 \quad 2.38 \mathrm{e}-02 \quad 0.190 .853$

CORROSION_LAG:RH7OCHG $-1.58 \mathrm{e}-03 \quad 2.27 \mathrm{e}-03 \quad-0.70 \quad 0.488$

RH70CHG:CHLORIDECHG $-3.96 \mathrm{e}-05 \quad 6.29 \mathrm{e}-04-0.06 \quad 0.950$

RH70CHG:PRECIPCHG:CHLORIDECHG 2.65e-07 2.98e-05 ०.01 0.993

CORROSION_LAG:RH7OCHG:PRECIPCHG:CHLORIDECHG $2.37 \mathrm{e}-081.71 \mathrm{e}-08$

$1.39 \odot .167$

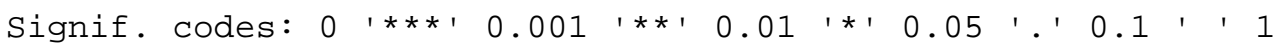

Residual standard error: 259 on 151 degrees of freedom

Multiple R-Squared: 0.541 , Adjusted R-squared: 0.516

F-statistic: 22.2 on 8 and 151 DF, p-value: $<2 e-16$

\section{D.3.3 "Dry" weather model (Group 3)}

$>\operatorname{summary}(\mathrm{AL7075.gp3.1m1)}$

Call:

$\operatorname{lm}$ (formula $=$ CORRCHG $\sim$ CORROSION_LAG + RH7OCHG + PRECIPCHG + CHLORIDECHG + CORROSION_LAG:RH7OCHG + RH7OCHG:CHLORIDECHG + RH7OCHG : PRECIPCHG : CHLORIDECHG + CORROSION_LAG:RH7OCHG:PRECIPCHG:CHLORIDECHG - 1, data = Corrosion.Data2 [Corrosion.Data2\$Metal == "AL7075" \& Corrosion. Data2\$Group $==3$,$] )$ 
Residuals:

Min 1Q Median 3Q Max

$\begin{array}{lllll}-284.80 & -26.53 & -5.91 & 13.06 & 840.36\end{array}$

Coefficients:

Estimate Std. Error $t$ value $\operatorname{Pr}(>|t|)$

CORROSION_LAG 2.04e-01 7.24e-02 2.81 0.0052 **

RH70CHG 3.93e-01 2.19e-01 1.790 .0745$.

PRECIPCHG $-4.71 \mathrm{e}-01 \quad 1.21 \mathrm{e}+0 \odot-0.390 .6971$

CHLORIDECHG 5.11e-03 $1.21 \mathrm{e}-02 \quad 0.42 \quad 0.6727$

CORROSION_LAG:RH70CHG $-2.10 \mathrm{e}-03 \quad 1.23 \mathrm{e}-03 \quad-1.700 .0903$.

RH70CHG:CHLORIDECHG $1.10 \mathrm{e}-03 \quad 3.33 \mathrm{e}-043.310 .0010$ **

RH70CHG:PRECIPCHG:CHLORIDECHG -6.36e-05 2.09e-05 -3.05 0.0025 **

CORROSION_LAG:RH7OCHG:PRECIPCHG:CHLORIDECHG 2.28e-07 4.96e-@8

$4.606 .2 \mathrm{e}-06 * * *$

$-$

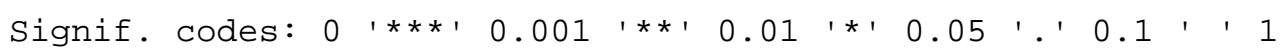

Residual standard error: 79.5 on 321 degrees of freedom

Multiple R-Squared: 0.525 , Adjusted R-squared: 0.513

F-statistic: 44.3 on 8 and 321 DF, p-value: $<2 e-16$

\section{D.4 Linear models for CORRCHG in Steel}

\section{D.4.1 "Extreme" weather model (Group 1)}

$>\operatorname{summary}($ Steel.gp1.lm1)

Call:

$1 \mathrm{~m}$ (formula $=$ CORRCHG $\sim$ CORROSION_LAG + RH7OCHG + PRECIPCHG +

CHLORIDECHG + CORROSION_LAG:RH7OCHG + RH7OCHG:CHLORIDECHG +

RH7OCHG:PRECIPCHG:CHLORIDECHG +

CORROSION_LAG:RH7OCHG:PRECIPCHG:CHLORIDECHG - 1, data =

Corrosion.Data2 [Corrosion. Data2\$Metal == "Steel" \&

Corrosion. Data2\$Group == 1, ])

Residuals: 
Min 1Q Median 3Q Max

$-23361-4699162354534705$

Coefficients:

Estimate Std. Error $t$ value $\operatorname{Pr}(>|t|)$

CORROSION_LAG $-6.56 \mathrm{e}-02 \quad 1.74 \mathrm{e}-01 \quad-0.38 \quad 0.71$

RH70CHG $8.87 \mathrm{e}+01 \quad 6.55 \mathrm{e}+01 \quad 1.35 \quad 0.18$

PRECIPCHG $4.16 \mathrm{e}+02 \quad 3.94 \mathrm{e}+02 \quad 1.06 \quad 0.30$

CHLORIDECHG $3.15 \mathrm{e}-01 \quad 4.14 \mathrm{e}-01 \quad 0.76 \quad 0.45$

CORROSION_LAG:RH7OCHG $3.54 \mathrm{e}-03 \quad 2.93 \mathrm{e}-03 \quad 1.21 \quad 0.23$

RH70CHG:CHLORIDECHG $1.86 \mathrm{e}-02 \quad 1.12 \mathrm{e}-02 \quad 1.660 .10$

RH70CHG:PRECIPCHG:CHLORIDECHG $-3.33 \mathrm{e}-04 \quad 1.01 \mathrm{e}-03 \quad-0.33 \quad 0.74$

CORROSION_LAG:RH7OCHG:PRECIPCHG:CHLORIDECHG - 7.78e-09 1.03e-08 -

0.760 .45

Residual standard error: 10700 on 63 degrees of freedom

Multiple R-Squared: 0.835 , Adjusted R-squared: 0.814

F-statistic: 39.9 on 8 and 63 DF, p-value: $<2 e-16$

\section{D.4.2 "Wet" weather model (Group 2)}

$>\operatorname{summary}($ Steel.gp2.lm1)

Call:

$1 \mathrm{~m}$ (formula $=$ CORRCHG $\sim$ CORROSION_LAG + RH7OCHG + PRECIPCHG + CHLORIDECHG + CORROSION_LAG:RH7OCHG + RH7OCHG:CHLORIDECHG + RH7OCHG:PRECIPCHG:CHLORIDECHG + CORROSION_LAG:RH7OCHG:PRECIPCHG:CHLORIDECHG - 1, data = Corrosion.Data2 [Corrosion.Data2\$Metal == "Steel" \& Corrosion. Data2 $\$$ Group $==2$,$] )$

Residuals:

Min 1Q Median 3Q Max

$-22332-4648-694383356121$

Coefficients:

Estimate Std. Error $t$ value $\operatorname{Pr}(>|t|)$ 


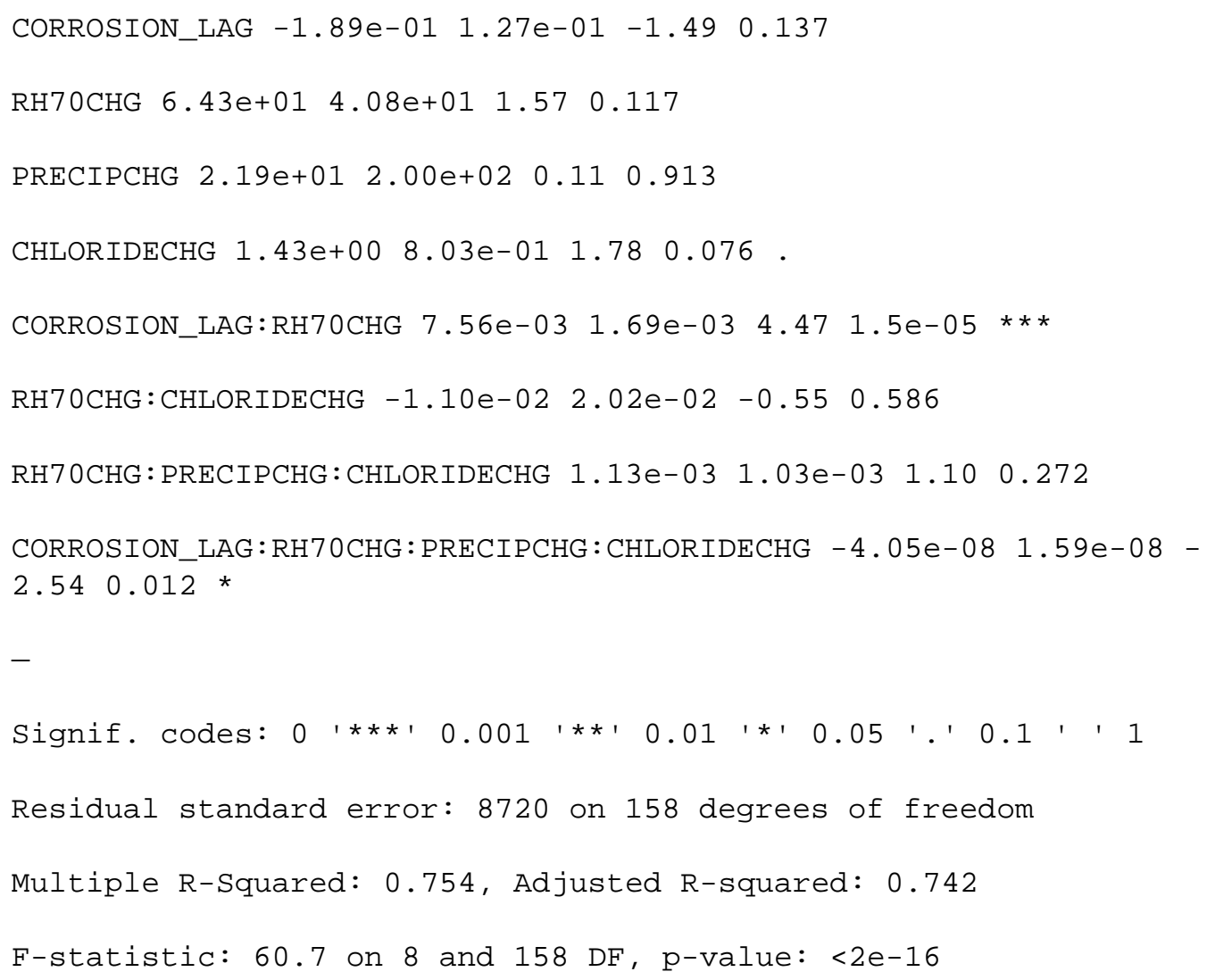

\section{D.4.3 "Dry" weather model (Group 3)}

$>$ summary(Steel.gp3.lm1)

Call:

$\operatorname{lm}$ (formula $=$ CORRCHG $\sim$ CORROSION_LAG + RH7OCHG + PRECIPCHG + CHLORIDECHG + CORROSION_LAG:RH7OCHG + RH7OCHG:CHLORIDECHG + RH7OCHG:PRECIPCHG:CHLORIDECHG + CORROSION_LAG:RH7OCHG:PRECIPCHG:CHLORIDECHG -1, data = Corrosion.Data2 [Corrosion.Data2\$Metal == "Steel" \&

Corrosion. Data2\$Group == 3, ])

Residuals:

Min $1 Q$ Median 3Q Max

$\begin{array}{lllll}-9677 & -2374 & -556 & 2027 & 15976\end{array}$

Coefficients:

Estimate Std. Error $t$ value $\operatorname{Pr}(>|t|)$

CORROSION_LAG 2.45e-01 5.85e-02 4.18 3.7e-05***

RH70CHG $4.77 \mathrm{e}+01 \quad 1.08 \mathrm{e}+01 \quad 4.44 \quad 1.2 \mathrm{e}-05$ *** 
PRECIPCHG $1.49 \mathrm{e}+02 \quad 6.03 \mathrm{e}+01 \quad 2.47 \quad 0.01394$ *

CHLORIDECHG 8.50e-01 5.68e-01 $1.50 \quad 0.13565$

CORROSION_LAG:RH70CHG $-3.99 \mathrm{e}-03 \quad 1.13 \mathrm{e}-03 \quad-3.540 .00046$ ***

RH70CHG:CHLORIDECHG 4.99e-02 1.62e-02 3.07 ๑.00228 **

RH70CHG:PRECIPCHG:CHLORIDECHG - 4.82e-03 $1.17 \mathrm{e}-03 \quad-4.13 \quad 4.6 \mathrm{e}-05$ $* * *$

CORROSION_LAG:RH7OCHG:PRECIPCHG:CHLORIDECHG $1.73 \mathrm{e}-07 \quad 2.77 \mathrm{e}-08$ $6.241 .3 e-09 * * *$

$-$

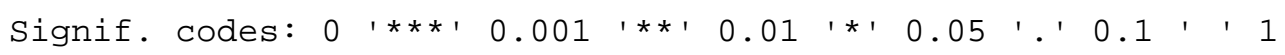
Residual standard error: 3750 on 325 degrees of freedom Multiple R-Squared: 0.735 , Adjusted R-squared: 0.728

F-statistic: 112 on 8 and 325 DF, p-value: $<2 e-16$

\section{D.5 Linear models for CORRCHG in Copper}

\section{D.5.1 “Extreme" weather model (Group 1)}

$>\operatorname{summary}(\mathrm{Cu} \cdot \mathrm{gp} 1 . \mathrm{Im} 1)$

Call:

$\mathrm{lm}$ (formula $=$ CORRCHG $\sim$ CORROSION_LAG + RH7OCHG + PRECIPCHG + CHLORIDECHG + CORROSION_LAG:RH7OCHG + RH7OCHG:CHLORIDECHG + RH7OCHG:PRECIPCHG:CHLORIDECHG + CORROSION_LAG:RH7OCHG:PRECIPCHG:CHLORIDECHG - 1 , data = Corrosion.Data2 [Corrosion.Data2\$Metal == "Cu" \& Corrosion. Data2\$Group == 1, ])

Residuals:

Min 1Q Median 3Q Max

$\begin{array}{lllll}-2564.1 & -969.7 & -47.7 & 849.6 & 3159.6\end{array}$

Coefficients:

Estimate Std. Error $t$ value $\operatorname{Pr}(>|t|)$

CORROSION_LAG $1.50 \mathrm{e}-01 \quad 2.57 \mathrm{e}-010.580 .562$

RH70CHG $3.32 \mathrm{e}+01 \quad 1.31 \mathrm{e}+01 \quad 2.54 \quad 0.015$ * 
PRECIPCHG $2.35 \mathrm{e}+01 \quad 6.85 \mathrm{e}+01 \quad 0.34 \quad 0.733$

CHLORIDECHG $3.57 \mathrm{e}-01 \quad 3.77 \mathrm{e}-01 \quad 0.95 \quad 0.349$

CORROSION_LAG:RH70CHG $4.89 \mathrm{e}-05 \quad 4.50 \mathrm{e}-03 \quad 0.01 \quad 0.991$

RH70CHG:CHLORIDECHG $-4.89 \mathrm{e}-03 \quad 6.43 \mathrm{e}-03 \quad-0.76 \quad 0.451$

RH70CHG:PRECIPCHG:CHLORIDECHG $-1.95 \mathrm{e}-04 \quad 2.06 \mathrm{e}-04 \quad-0.95 \quad 0.347$

CORROSION_LAG:RH7OCHG:PRECIPCHG:CHLORIDECHG $2.04 \mathrm{e}-08 \quad 1.66 \mathrm{e}-08$

1.230 .227

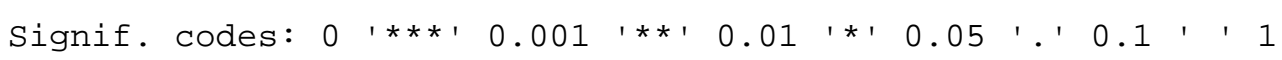

Residual standard error: 1490 on 43 degrees of freedom

Multiple R-Squared: 0.834 , Adjusted R-squared: 0.804

F-statistic: 27.1 on 8 and 43 DF, p-value: $2.09 \mathrm{e}-14$

\section{D.5.2 "Wet" weather model (Group 2)}

$>\operatorname{summary}(\mathrm{Cu} \cdot \mathrm{gp} 2 \cdot \operatorname{lm} 1)$

Call:

$\operatorname{lm}$ (formula $=$ CORRCHG $\sim$ CORROSION_LAG + RH7OCHG + PRECIPCHG + CHLORIDECHG + CORROSION_LAG:RH7OCHG + RH70CHG:CHLORIDECHG + RH7OCHG:PRECIPCHG:CHLORIDECHG + CORROSION_LAG:RH7OCHG:PRECIPCHG:CHLORIDECHG - 1, data = Corrosion.Data2 [Corrosion. Data2\$Metal == "Cu" \& Corrosion. Data2 $\$$ Group $==2$,$] )$

Residuals:

Min 1Q Median 3Q Max $\begin{array}{lllll}-2600 & -852 & -128 & 539 & 4588\end{array}$

Coefficients:

Estimate Std. Error $t$ value $\operatorname{Pr}(>|t|)$

CORROSION_LAG 2.68e-01 $1.11 \mathrm{e}-012.420 .018$ *

RH70CHG $5.55 \mathrm{e}+\odot \odot \quad 7.88 \mathrm{e}+\odot \odot \quad 0.7 \odot \quad 0.483$

PRECIPCHG $2.99 \mathrm{e}+01 \quad 4.33 \mathrm{e}+01 \quad 0.69 \quad 0.491$

CHLORIDECHG $-1.22 \mathrm{e}-02 \quad 2.09 \mathrm{e}-01-0.06 \quad 0.954$ 
CORROSION_LAG:RH70CHG $-8.87 \mathrm{e}-04 \quad 1.77 \mathrm{e}-03-0.50 \quad 0.617$

RH7०CHG: CHLORIDECHG $7.22 \mathrm{e}-03 \quad 4.55 \mathrm{e}-03 \quad 1.590 .116$

RH70CHG:PRECIPCHG:CHLORIDECHG -3.16e-04 2.08e-04 - $1.52 \quad 0.132$

CORROSION_LAG:RH70CHG:PRECIPCHG : CHLORIDECHG - $1.48 \mathrm{e}-091.04 \mathrm{e}-08$ 0.140 .887

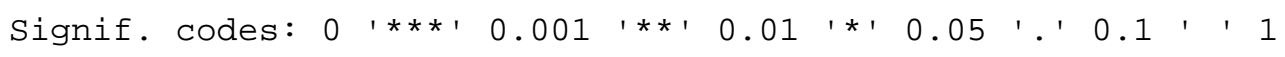
Residual standard error: 1290 on 92 degrees of freedom Multiple R-Squared: $\odot .756$, Adjusted R-squared: 0.734 F-statistic: 35.6 on 8 and 92 DF, p-value: $<2 e-16$

\section{D.5.3 "Dry" weather model (Group 3)}

$>\operatorname{summary}(\mathrm{Cu} \cdot \mathrm{gp} 3 . \operatorname{lm} 1)$

Call:

$\operatorname{lm}$ (formula $=$ CORRCHG $\sim$ CORROSION_LAG + RH7OCHG + PRECIPCHG + CHLORIDECHG + CORROSION_LAG:RH70CHG + RH70CHG:CHLORIDECHG + RH7OCHG : PRECIPCHG : CHLORIDECHG + CORROSION_LAG:RH7OCHG:PRECIPCHG:CHLORIDECHG - 1, data = Corrosion. Data2 [Corrosion. Data2\$Metal == "Cu" \& Corrosion. Data2\$Group == 3, ])

Residuals:

Min 1Q Median 3Q Max

$-1397-486-1353473026$

Coefficients:

Estimate Std. Error $t$ value $\operatorname{Pr}(>|t|)$

CORROSION_LAG 5.31e-01 5.62e-02 9.45<2e-16***

RH70CHG $9.11 \mathrm{e}+0 \odot \quad 2.30 \mathrm{e}+0 \odot \quad 3.97 \quad 9.5 \mathrm{e}-05 \quad * * *$

PRECIPCHG $-1.80 \mathrm{e}+01 \quad 1.29 \mathrm{e}+01-1.39 \quad 0.165$

CHLORIDECHG 2.90e-01 $1.15 \mathrm{e}-012.520 .012$ *

CORROSION_LAG:RH70CHG - 2.59e-03 $1.11 \mathrm{e}-03-2.340 .020$ *

RH70CHG:CHLORIDECHG $-5.57 e-03 \quad 3.57 e-03-1.56 \quad 0.121$ 
RH7OCHG:PRECIPCHG:CHLORIDECHG $7.83 e-05$ 2.53e-04 $\bullet .310 .757$

CORROSION_LAG:RH7OCHG:PRECIPCHG:CHLORIDECHG $7.92 \mathrm{e}-08 \quad 8.29 \mathrm{e}-08$ $\odot .96 \odot .340$

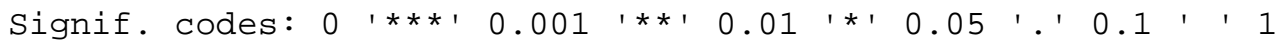
Residual standard error: 711 on 253 degrees of freedom Multiple R-Squared: 0.756 , Adjusted R-squared: 0.748 F-statistic: 98 on 8 and 253 DF, p-value: $<2 e-16$ 


\section{Appendix E: Plots of Regression Models for Selected Sites and Metals}

Figure E-1. Depiction of modeled results vs. actual results for Guam (Anderson), AL7075.

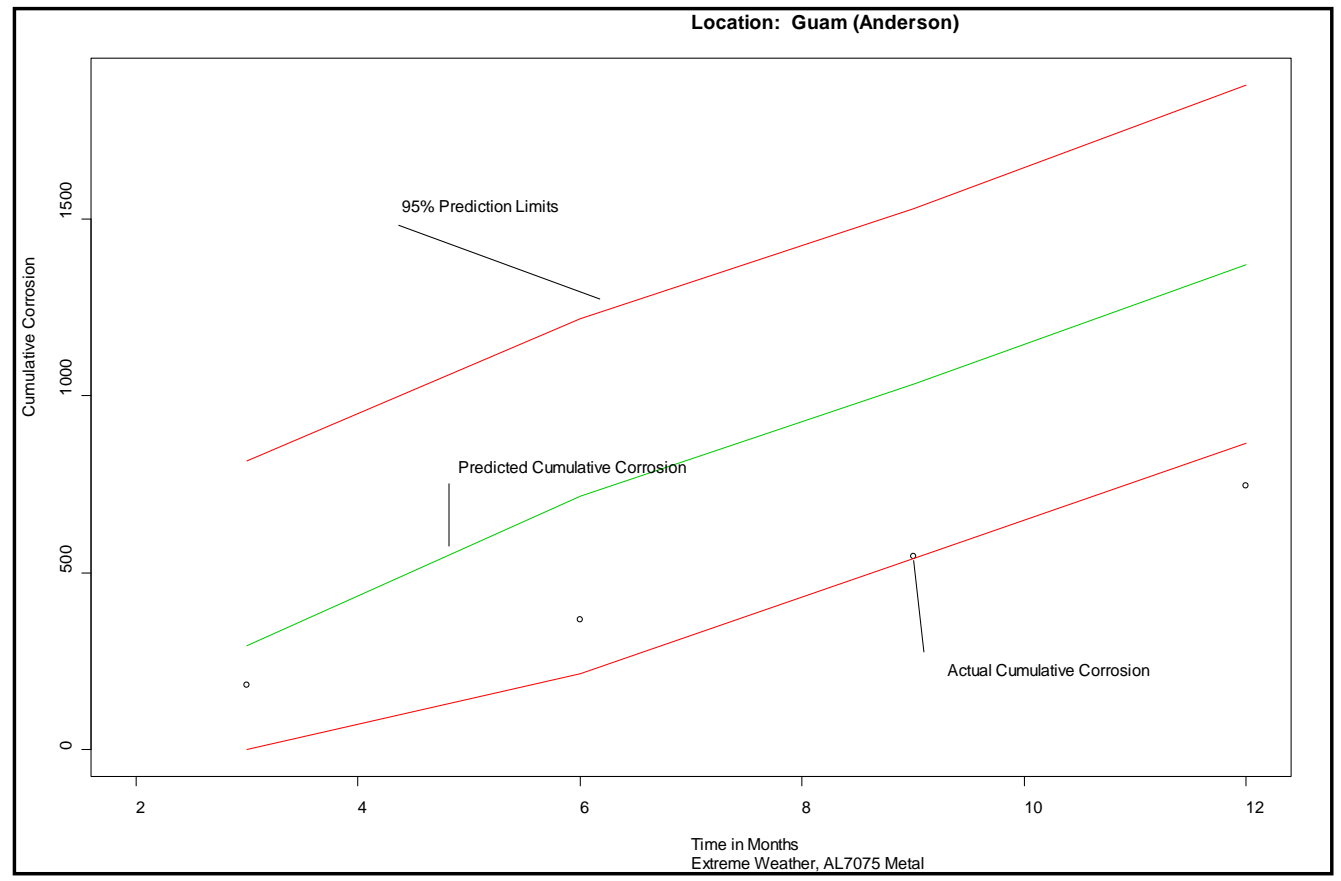

Figure E-2. Depiction of modeled results vs. actual results for Eareckson, $\mathrm{Cu}$.

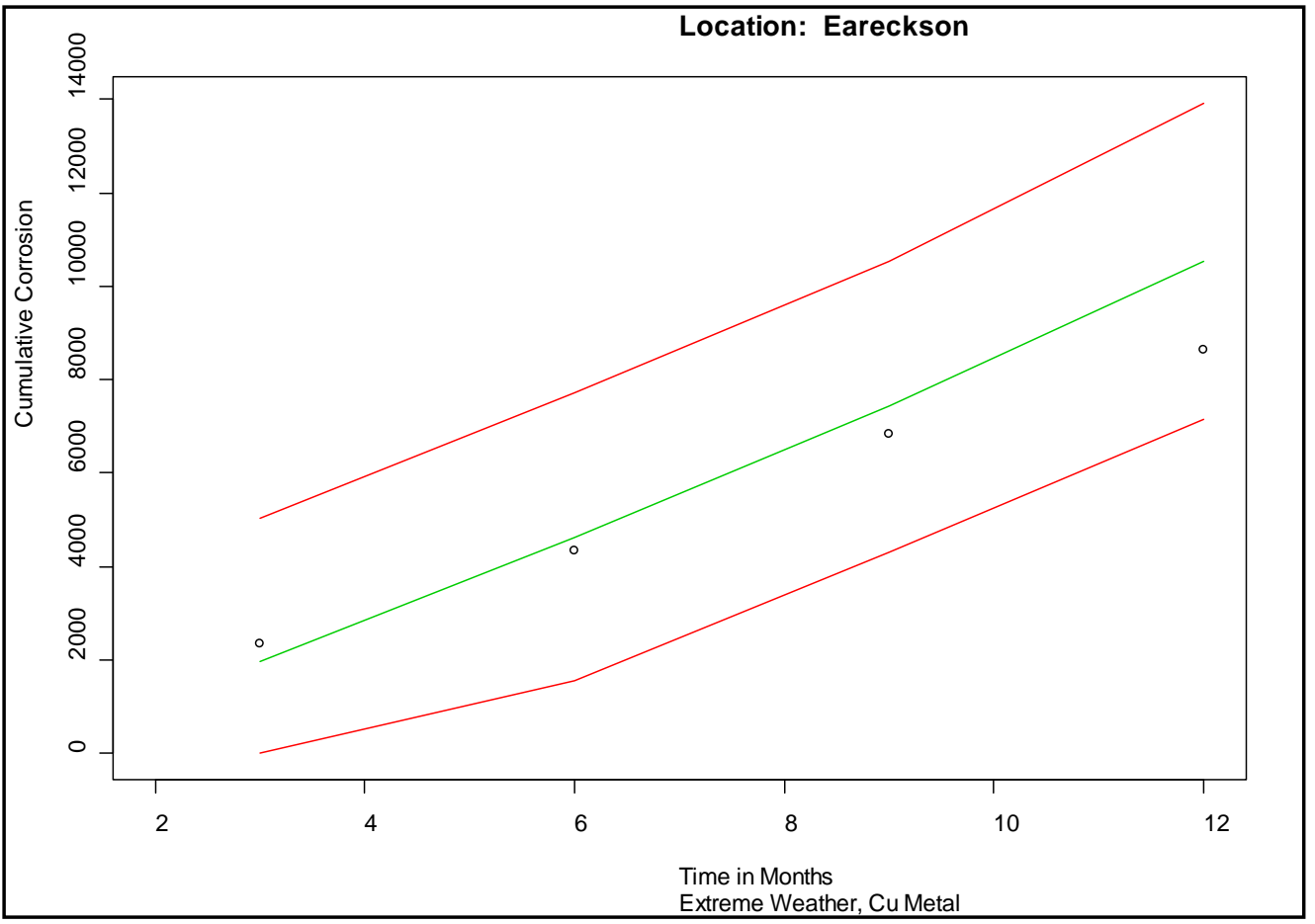


Figure E-3. Depiction of modeled results vs. actual results for Balad (164), AL2024.

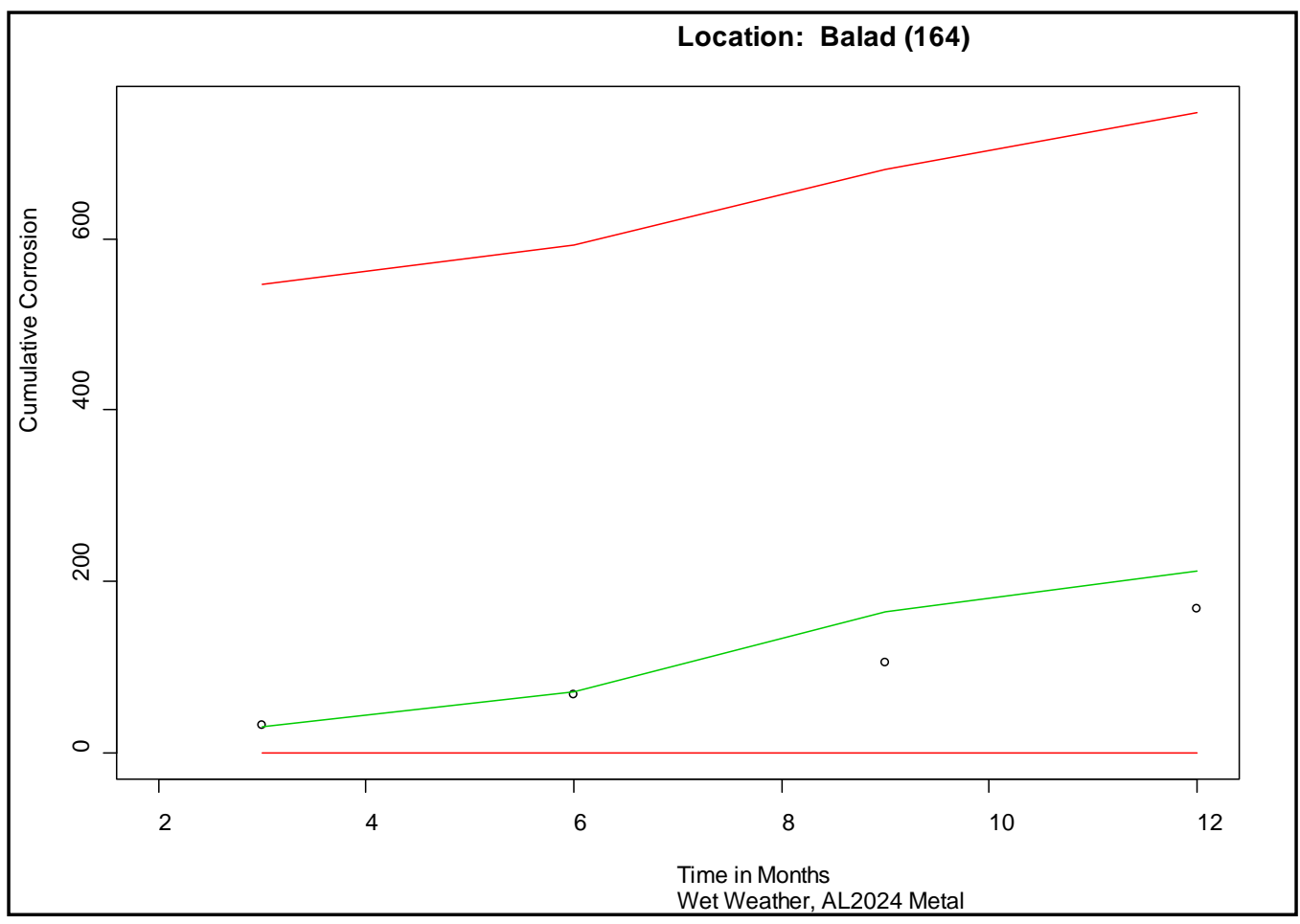

Figure E-4. Depiction of modeled results vs. actual results for DAB Arpt, ${ }^{\star}$ AL6061.

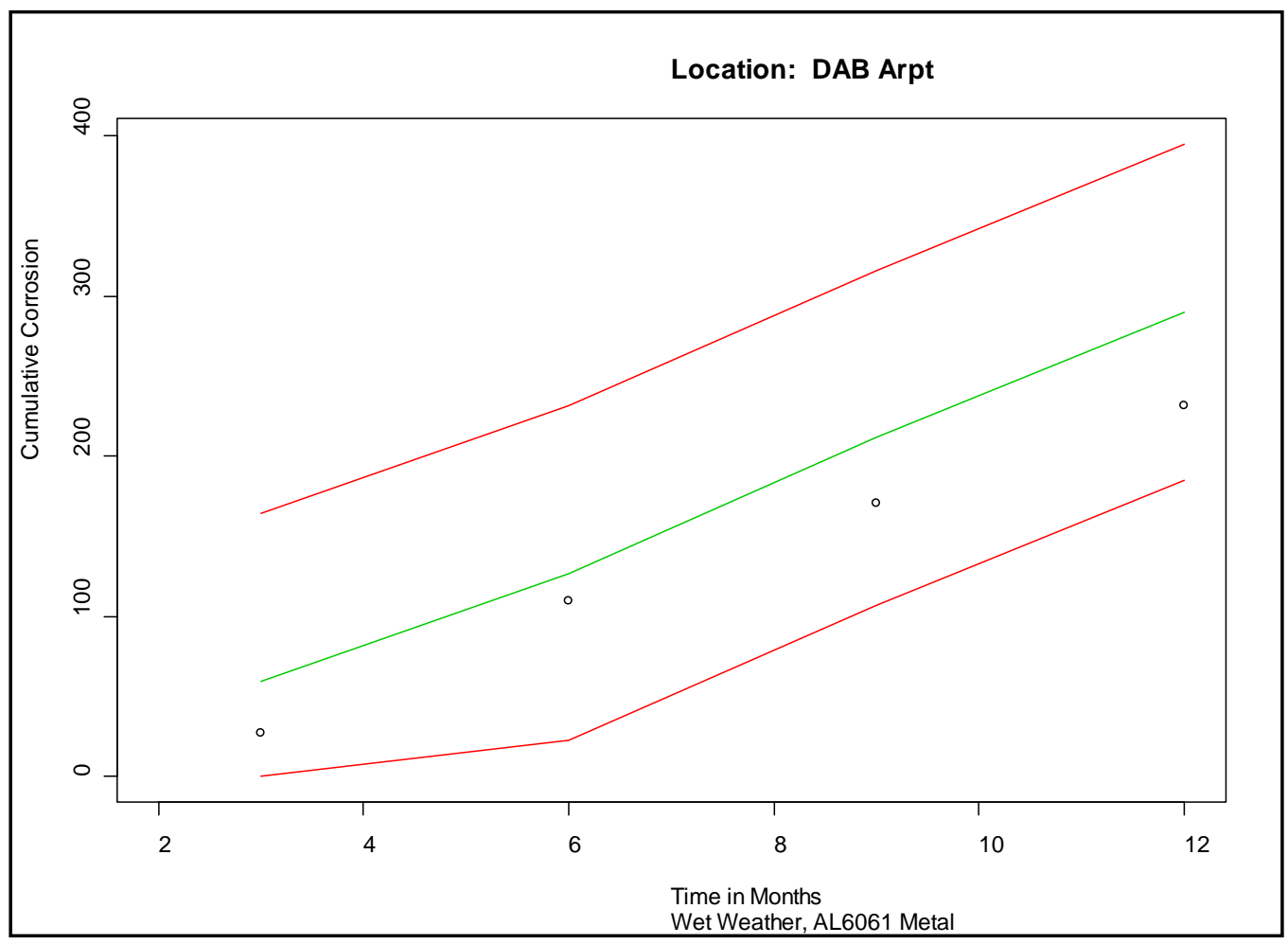

* Daytona Beach International Airport (DAB). 
Figure E-5. Depiction of modeled results vs. actual results for Athens, AL6061.

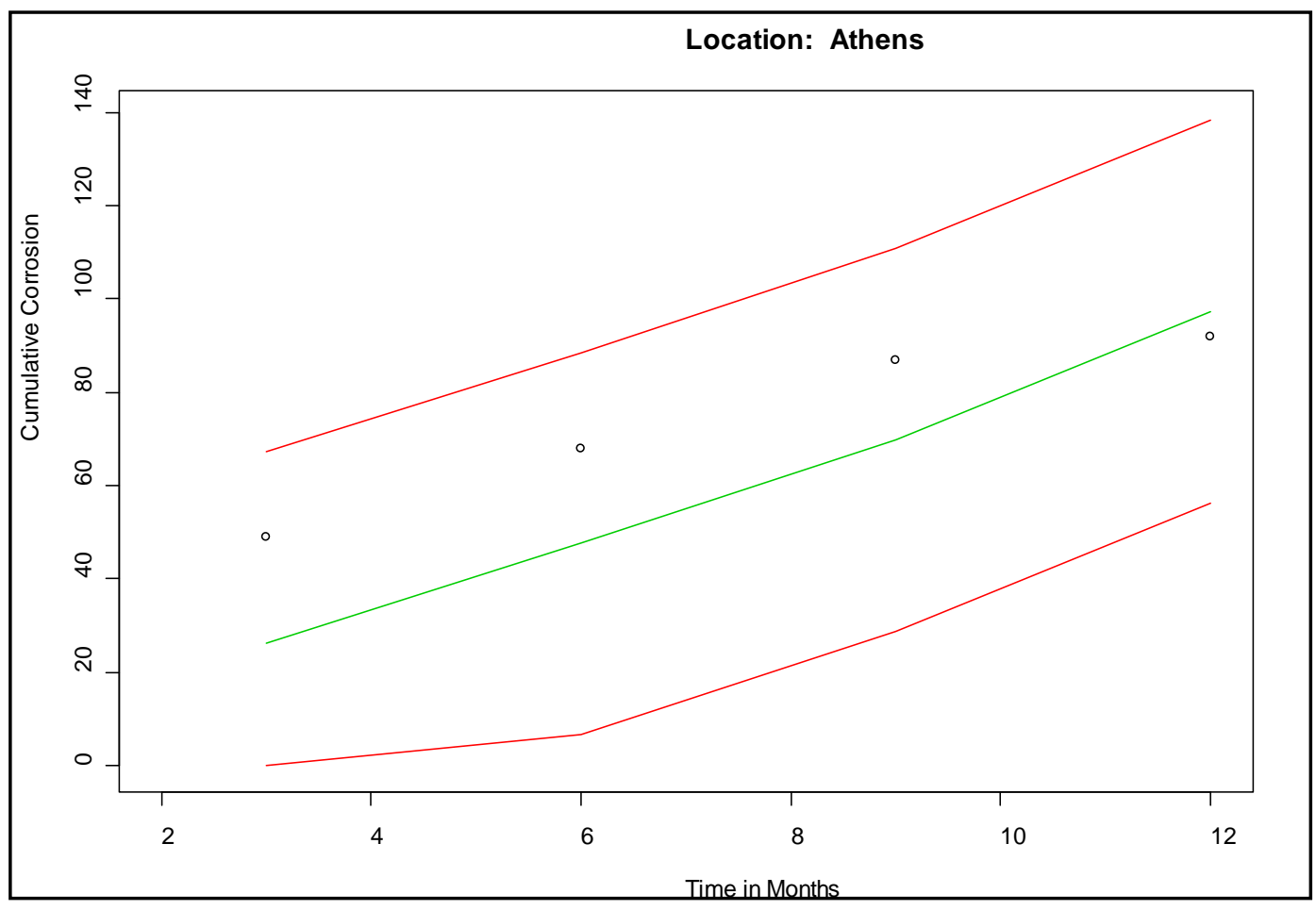

Figure E-6. Depiction of modeled results vs. actual results for Dover, Steel.

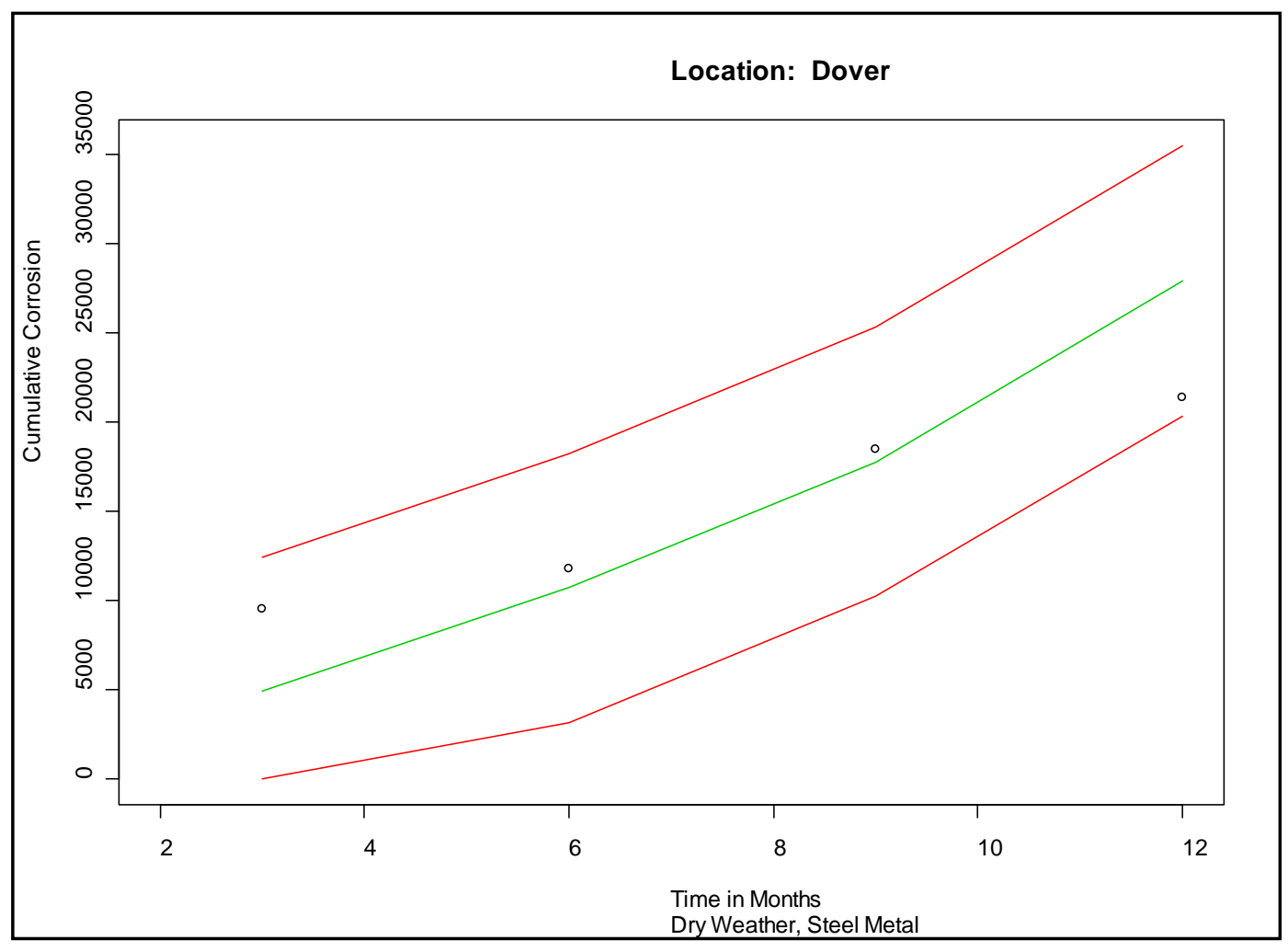




\section{References}

American Society for Testing and Materials (ASTM) International. 2010. Standard Specification for Aluminum-Alloy 6061-T6 Standard Structural Profiles. ASTM B308/B308M-02. West Conshohocken, PA: ASTM.

_ 2013a. Standard Specification for Steel Bar, Carbon and Alloy, Cold-Finished. ASTM A108. West Conshohocken, PA: ASTM.

— 2013b. Standard Specification for Copper Sheet, Strip, Plate, and Rolled Bar. ASTM B152. West Conshohocken, PA: ASTM.

Drozdz, Susan A., William H. Abbott, and J ana L. J ackson. 2007. Measuring the Rates and Impact of Corrosion on DoD on Equipment and Installations: Final Report on Project AR-F-11. ERDC/ CERL TR-07-18. Champaign, IL: Engineer Research and Development Center, Construction Engineering Research Laboratory (ERDC-CERL), http://acwc.sdp.sirsi.net/client/search/asset/1002573

Summitt, Robert, and Fret T Fink. 1980. PACER LIME: An Environmental Corrosion Severity Classification System. AFWAL-TR-80-4102 Part-1/ADA100496. Wright-Patterson Air Force Base, OH: Materials Laboratory, Air Force Wright Aeronautical Laboratories, Air Force Systems Command,| http://www.dtic.mil/dtic/tr/fulltext/u2/a100496.pdf 


\title{
Acronyms and Abbreviations
}

\author{
Term \\ Definition \\ AFCCC \\ Air Force Combat Climatology Center \\ AMSAA \\ US Army Materiel Systems Analysis Activity \\ ANSI \\ American National Standards Institute \\ AR \\ Army Regulation \\ ASTM \\ American Society for Testing and Materials \\ CAA \\ Center for Army Analysis \\ CEERD \\ US Army Corps of Engineers, Engineer Research and Development Center \\ CERL \\ Construction Engineering Research Laboratory \\ COBRA \\ Comprehensive Omnibus Budget Reconciliation Act \\ CRREL \\ Cold Regions Research and Engineering Laboratory \\ $\mathrm{DAB}$ \\ Daytona Beach International Airport \\ DoD \\ U.S. Department of Defense \\ ERDC \\ Engineer Research and Development Center \\ ERDC-CERL \\ Engineer Research and Development Center, Construction Engineering \\ Research Laboratory \\ ERDC-CRREL Engineer Research and Development Center, Cold Regions Research and \\ Engineering Laboratory \\ GCM Global Climate Model \\ GIS \\ Geographic Information System \\ HQDA \\ Headquarters, Department of the Army \\ HQUSACE \\ Headquarters, U.S. Army Corps of Engineers \\ ID \\ Identification \\ IFS \\ (Army) Integrated Facilities System \\ IMA \\ Installation Management Agency \\ NSN \\ National Supply Number \\ NW \\ Northwest \\ O\&M \\ Operations and Maintenance \\ OMB \\ Office of Management and Budget \\ OSAF \\ Optimal Stationing of Army Forces \\ OSD \\ Office of the Secretary of Defense \\ PAM \\ Partitioning Around Medoids \\ SAR \\ Same As Report
}




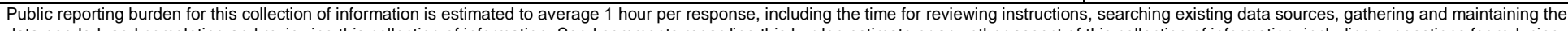

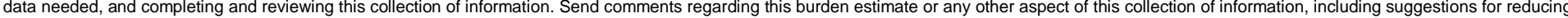

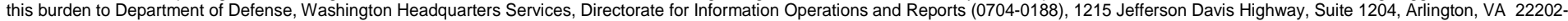

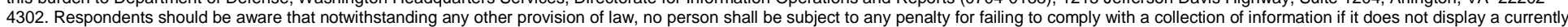
valid OMB control number. PLEASE DO NOT RETURN YOUR FORM TO THE ABOVE ADDRESS.

\begin{tabular}{l|l} 
valid OMB control number. PLEASE DO NOT RETURN YOUR FORM TO THE ABOVE ADDRESS. \\
\hline 1. REPORT DATE (DD-MM-YYYY) 2. REPOR
\end{tabular}

\begin{tabular}{|c|cc}
$09 / 12 / 2017$ & Final \\
\hline
\end{tabular}

\section{TITLE AND SUBTITLE}

Development of a Predictive Corrosion Model Using Locality-Specific Corrosion Indices

3. DATES COVERED (From - To)

5a. CONTRACT NUMBER

5b. GRANT NUMBER

5c. PROGRAM ELEMENT

622720A896

\section{AUTHOR(S)}

Sean W. Morefield

\section{5d. PROJECT NUMBER}

5e. TASK NUMBER

5f. WORK UNIT NUMBER

L4F5G1

7. PERFORMING ORGANIZATION NAME(S) AND ADDRESS(ES)

U.S. Army Engineer Research and Development Center (ERDC)

Construction Engineering Research Laboratory (CERL)

PO Box 9005,

Champaign, IL 61826-9005

8. PERFORMING ORGANIZATION REPORT NUMBER

ERDC/CERL TR-17-31

\section{SPONSORING / MONITORING AGENCY NAME(S) AND ADDRESS(ES)}

Headquarters, U.S. Army Corps of Engineers

441 G St., NW

Washington, DC 20314-5000

10. SPONSOR/MONITOR'S ACRONYM(S) HQDA

11. SPONSOR/MONITOR'S REPORT NUMBER(S)

\section{DISTRIBUTION I AVAILABILITY STATEMENT}

Approved for public release; distribution is unlimited.

\section{SUPPLEMENTARY NOTES}

\section{ABSTRACT}

The U.S. Department of Defense has characterized the current approach to corrosion maintenance, which is based on simply finding and fixing damage before it becomes a concern, as inadequate to maintain mission-critical equipment and facilities to support stationing decisions. There is a need to go beyond corrosion prediction and management approaches to consider the impact of climate change on stationing decisions. To address this concern, there is a need to develop defensible, accurate approaches to project how certain installation metrics involving materials degradation are likely to change in the near future. The first step in creating a tool to meet this need is to determine how selected quantitative data, or chosen installation "metrics," will change over some specified period. This work developed and tested a corrosivity model capable of predicting corrosivity at specific sites.

\section{SUBJECT TERMS}

Corrosion, Climatic factors, Climatic changes--Forecasting, Military bases, Computer simulation

\begin{tabular}{|l|c|}
\hline 16. SECURITY CLASSIFICATION OF: \\
\hline $\begin{array}{c}\text { a. REPORT } \\
\text { Unclassified }\end{array}$ & b. ABSTRACT \\
Unclassified & c. THIS PAGE \\
Unclassified
\end{tabular}

\begin{tabular}{|c|c|c|}
\hline $\begin{array}{c}\text { 17. LIMITATION } \\
\text { OF ABSTRACT }\end{array}$ & $\begin{array}{c}\text { 18. NUMBER } \\
\text { OF PAGES }\end{array}$ & $\begin{array}{c}\text { 19a. NAME OF RESPONSIBLE PERSON } \\
\text { SAR }\end{array}$ \\
\cline { 3 - 3 } & 62 & $\begin{array}{c}\text { 19b. TELEPHONE NUMBER } \\
\text { (include area code) }\end{array}$ \\
\hline
\end{tabular}

